\title{
Study of Advanced Materials for Aircraft Jet Engines Using Quantitative Metallography
}

\author{
Juraj Belan \\ University of Žilina, Faculty of Mechanical Engineering, \\ Department of Materials Engineering, Žilina \\ Slovak Republic
}

\section{Introduction}

The aerospace industry is one of the biggest consumers of advanced materials because of its unique combination of mechanical and physical properties and chemical stability. Highly alloyed stainless steel, titanium alloys and nickel based superalloys are mostly used for aerospace applications. High alloyed stainless steel is used for the shafts of aero engine turbines, titanium alloys for compressor blades and finally nickel base superalloys are used for the most stressed parts of the jet engine - the turbine blades. Nickel base superalloys were used in various structural modifications: as cast polycrystalline, a directionally solidified, single crystal and in last year's materials which were produced by powder metallurgy.

So what exactly is a superalloy? Let us have a closer look to its definition. An interesting thing about it is that there is no standard definition of what constitutes a superalloy. The definitions which are provided in the various handbooks and reference books, although somewhat vague, are typically based on the service conditions in which superalloys are utilised. The most concise definition might be that provided by Sims et al. (1987): "...superalloys are alloys based on Group VIII-A base elements developed for elevatedtemperature service, which demonstrate combined mechanical strength and surface stability." Superalloys are typically used at service temperatures above $540 \mathrm{C}^{\circ}\left(1000 \mathrm{~F}^{\circ}\right)$, and within a wide range of fields and applications, such as components in turbine engines, nuclear reactors, chemical processing equipment and biomedical devices; by volume, its predominant use is in aerospace applications. Superalloys are processed by a wide range of techniques, such as investment casting, forging and forming, and powder metallurgy.

The superalloys are often divided into three classes based on the major alloying constituent: iron-nickel-based, nickel-based and cobalt-based. The iron-nickel-based superalloys are considered to have developed as an extension of stainless steel technology. Superalloys are highly alloyed, and a wide range of alloying elements are used to enhance specific microstructural features (and - therefore - mechanical properties). Superalloys can be further divided into three additional groups based on their primary strengthening mechanism:

- $\quad$ solid-solution strengthened; 
- $\quad$ precipitation strengthened;

- $\quad$ oxide dispersion strengthened (ODS) alloys.

Solid-solution strengthening results from lattice distortions caused by solute atoms. These solute atoms produce a strain field which interacts with the strain field associated with the dislocations and acts to impede the dislocation motion. In precipitation strengthened alloys, coherent precipitates resist dislocation motion. At small precipitate sizes, strengthening occurs by the dislocation cutting of the precipitates, while at larger precipitate sizes strengthening occurs through Orowan looping. Oxide dispersion strengthened alloys are produced by mechanical alloying and contain fine incoherent oxide particles which are harder than the matrix phase and which inhibit dislocation motion by Orowan looping (MacSleyne 2008).

Figure 1. provides a representation of the alloy and process development which has occurred since the first superalloys began to appear in the 1940s; the data relates to the materials and processes used in turbine blading, such that the creep performance is a suitable measure for the progress which has been made. Various points emerge from a study of the figure. First, one can see that - for the blading application - cast rather than wrought materials are now preferred since the very best creep performance is then conferred. However, the first aerofoils were produced in wrought form. During this time, alloy development work - which saw the development of the first Nimonic alloys - enabled the performance of blading to be improved considerably; the vacuum introduction casting technologies which were introduced in the 1950s helped with this since the quality and cleanliness of the alloy were dramatically improved.

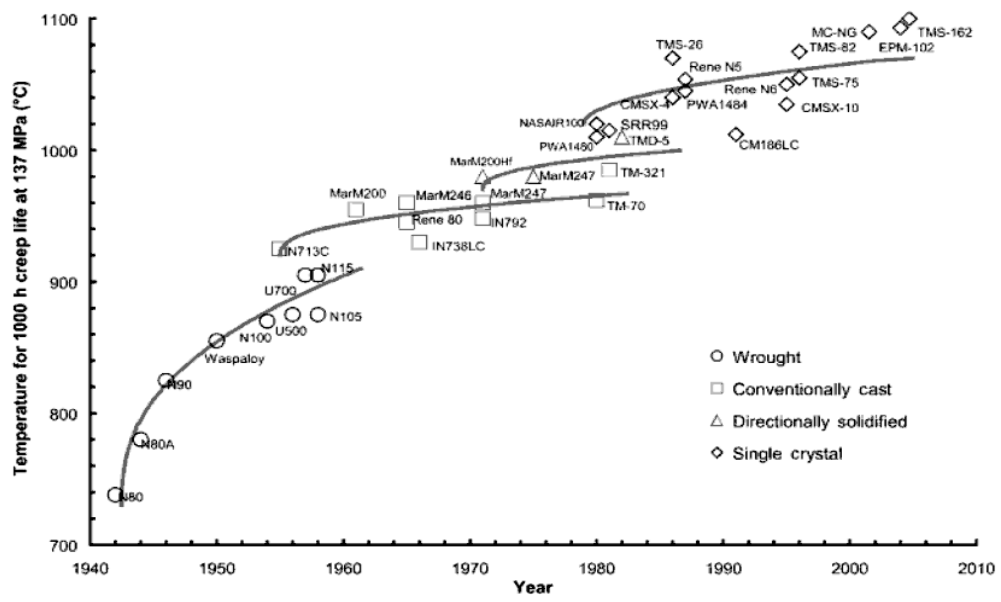

Fig. 1. Evolution of the high-temperature capability of superalloys over a 70 year period, since their emergence in the 1940s (Reed 2006).

Second, the introduction of improved casting methods and - later - the introduction of processing by directional solidification enabled significant improvements to be made; this was due to the columnar microstructures that were produced in which the transverse grain boundaries were absent (see Figure 2.) 


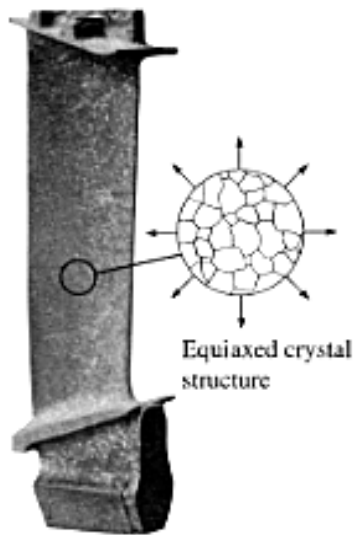

(a)

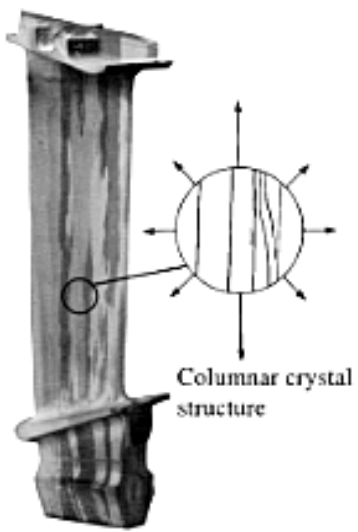

(b)

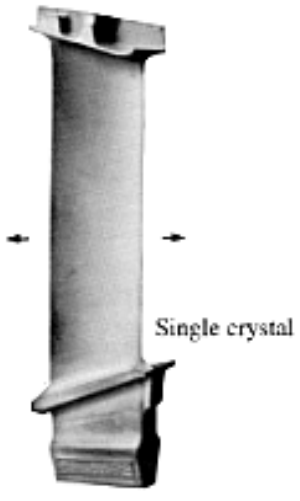

(c)

Fig. 2. Turbine blading in the (a) equiaxed-, (b) columnar- and (c) single-crystal forms.

Once this development had occurred, it was quite natural to remove the grain boundaries completely such that monocrystalline (single-crystal) superalloys were produced. This allowed, in turn, the removal of grain boundary strengthening elements such as boron and carbon which had traditionally been added, thereby enabling better heat treatments to reduce microsegregation and induced eutectic content, whilst avoiding incipient melting during heat treatment. The fatigue life is then improved.

Nowadays, single-crystal superalloys are being used in increasing quantities in the gas turbine engine; if the very best creep properties are required, then the turbine engineers turn to them (although it should be recognised that the use of castings in the columnar and equiaxed forms is still practiced in many instances).

In this chapter, a problem of polycrystalline (equiaxed) nickel base superalloy turbine blades - such as the most stressed parts of the aero jet engine - will be discussed.

The structure of polycrystalline Ni-based superalloys - depending on heat-treatment consists of a solid solution of elements in $\mathrm{Ni}(\gamma$-phase, an austenitic fcc matrix phase) and inter-metallic strengthening precipitate $\mathrm{Ni}_{3}(\mathrm{Al}, \mathrm{Ti})$ ( $\gamma^{\prime}$-phase, which is an ordered coherent precipitate phase with a LI2 structure). A schematic showing representative microstructures of both a wrought and a cast nickel-base superalloy is shown in Figure 3. The $\gamma^{\prime}$ precipitates in precipitate strengthened nickel-base superalloys remain coherent up to large precipitate sizes due to the small lattice mismatch between the matrix phase $\gamma$ and the $\gamma^{\prime}$ precipitates. The $\gamma^{\prime}$ precipitates are usually present in volume fractions in the range of $20-60 \%$, depending on the alloy (Sims et al. 1987), with typical shapes from the spherical at small sizes to cuboid at larger sizes, although more complex dendritic shapes are also observed in some cases (see Figure 4). The alignment of $\gamma^{\prime}$ precipitates along the elastically soft (100) directions is frequently observed. Nickel based superalloys are precipitation hardened, with a typical precipitate size of 0.25-0.5 $\mu \mathrm{m}$ for high temperature applications (Sims et al. 1987). 

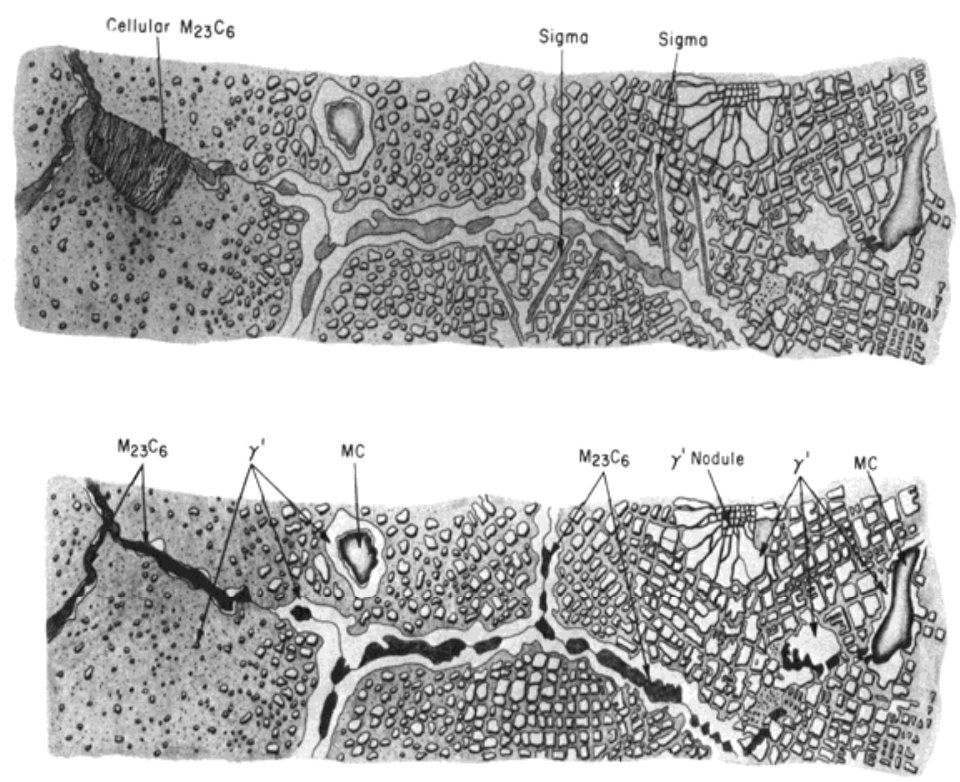

Fig. 3. Structure of a wrought and a cast nickel-base superalloy (M. J. Donachie \& S. J. Donachie 2002).
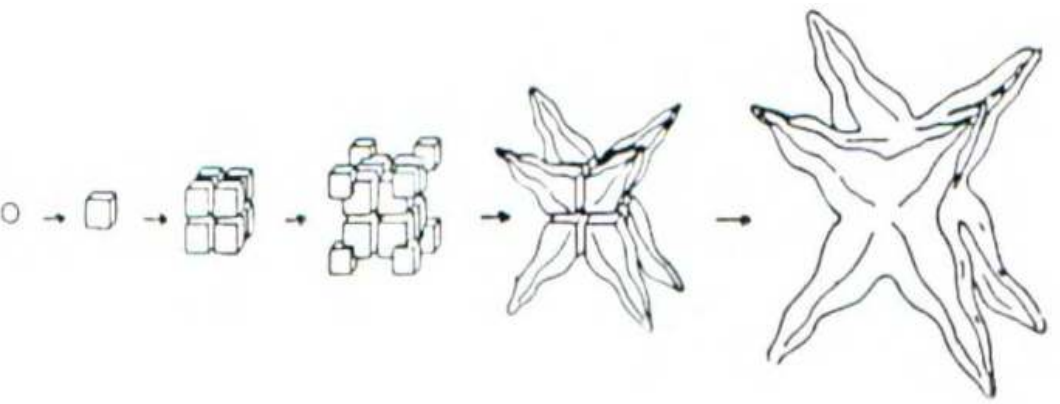

Fig. 4. Schematic showing the evolution of $\gamma^{\prime}$ morphology during continuous cooling. Sphere $\rightarrow$ cube $\rightarrow$ ogdoadically diced cubes $\rightarrow$ octodendrite $\rightarrow$ dendrite (Durand-Charre 1997).

In niobium-strengthened nickel-base superalloys - such as IN-718 - the principal strengthening phase is $\gamma^{\prime \prime}\left(\mathrm{Ni}_{3} \mathrm{Nb}\right)$, which has a bct ordered DO22 structure. When $\gamma^{\prime \prime}$ precipitates are observed, they form as disk-shaped precipitates on $\{100\}$ planes with a thickness of 5-9 $\mathrm{nm}$ and an average diameter of $60 \mathrm{~nm}$ (Durand-Charre 1997).

The next structural components are $\mathrm{MC}$ type primary carbides (created by such elements as $\mathrm{Cr}$ and $\mathrm{Ti}$ ) and $\mathrm{M}_{23} \mathrm{C}_{6}$ type secondary carbides (created by such elements as $\mathrm{Cr}, \mathrm{Co}$, Mo and W). However, except of these structural components, "unwanted" TCP (Topologically 
Close-Packed) phases are also presented, such as o-phase $A_{x} B_{y}(C r, M o)_{x}(F e, N i)_{y}, \mu$-phase $\mathrm{A}_{7} \mathrm{~B}_{6}(\mathrm{Co}, \mathrm{Fe}, \mathrm{Ni})_{7}(\mathrm{Mo}, \mathrm{W}, \mathrm{Cr})_{6}$, Laves phases $\mathrm{A}_{2} \mathrm{~B}(\mathrm{Fe}, \mathrm{Cr}, \mathrm{Mn}, \mathrm{Si})_{2}(\mathrm{Mo}, \mathrm{Ti}, \mathrm{Nb})$ and $\mathrm{A}_{3} \mathrm{~B}$ phases $\left(\pi \mathrm{Ni}_{3}(\mathrm{AlTa}), \eta \mathrm{Ni}_{3} \mathrm{Ti}, \delta \mathrm{Ni}_{3} \mathrm{Ta}\right.$ and $\left.\varepsilon(\mathrm{NiFeCo})_{3}(\mathrm{NbTi})\right)$. The shape and size of these structural components have a significant influence on final the mechanical properties of alloys and - mainly - on creep rupture life.

Although alloy-specific heat treatments are generally proprietary, the typical heat treatment of nickel-base superalloys consists of a solution treatment followed by an aging step (precipitation and coarsening). For additional details on alloy-specific heat treatments, see Sims et al. (1987) and M. J. Donachie \& S. J. Donachie (2002). Nickel-base superalloys are highly-alloyed: because of the complexity which this adds, many experimental studies use binary or ternary alloys as model alloy systems. The nickel-rich region of the binary Ni-Al alloy system is frequently used as a model alloy system. The Al-Ni phase diagram is shown in Figure 5, and we will use it to consider the typical heat treatments of nickel-base superalloys.

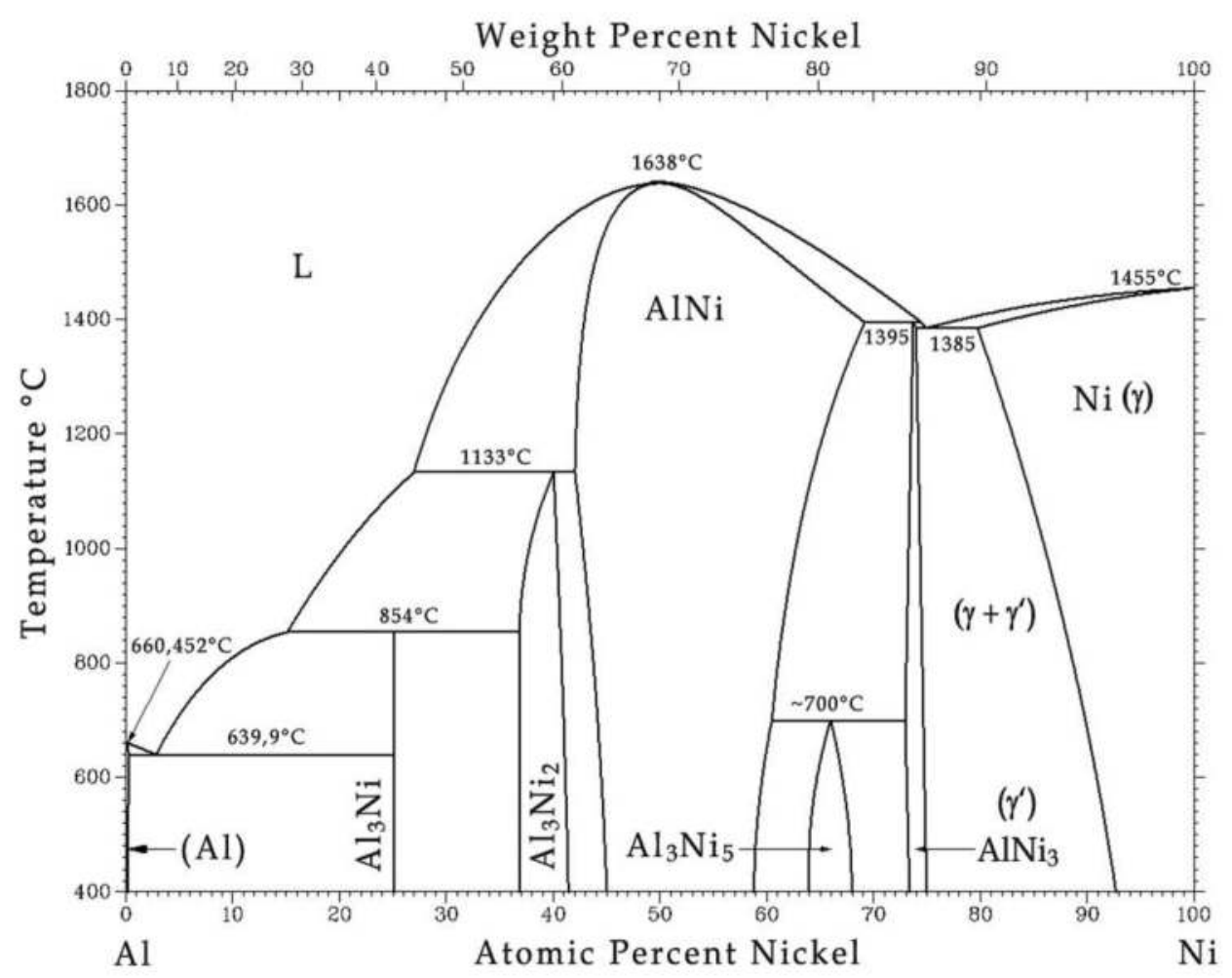

Fig. 5. Al-Ni phase diagram (ASM, 1992).

The solution treatment occurs above the $\gamma^{\prime}$ solvus and is required for the ordered $\gamma^{\prime}$ to go into the solution. The $\gamma^{\prime}$ solvus separates the $\gamma+\gamma^{\prime}$ and $\gamma$ regions in Figure 5. This is usually followed by a quench (air, water or oil, depending upon the alloy) to room temperature. The 
aging occurs at a temperature below the solvus temperature and allows for the homogeneous nucleation, growth and coarsening of $\gamma^{\prime}$, followed by air or furnace cooling to room temperature. Although heterogeneous nucleation is observed on grain boundaries and dislocations - for example - nucleation is primarily homogeneous. The temperature and duration of the aging treatment are selected so as to optimise the morphology, alignment and size distribution of $\gamma^{\prime}$ precipitates. The resulting microstructure, in addition to its dependence on heat-treatment parameters, is also dependent on the physical properties of the alloy (and their isotropic or anisotropic nature) such as the lattice mismatch, the coherent $\gamma^{\prime}$ interface energy, the volume fraction of $\gamma^{\prime}$ and the elastic properties of the matrix and precipitate.

Polycrystalline turbine blades typically work within a temperature range from $705^{\circ} \mathrm{C}$ up to $800^{\circ} \mathrm{C}$. As such, they must be protected from heat by various heat-proof layers; for example an alitise layer, MCrAlY coating or TBC (Thermal Barrier Coating). For this reason, dendrite arm-spacing, carbide size and distribution, morphology, the number and value of the $\gamma^{\prime}$ phase and protective layer degradation are very important structural characteristics for the prediction of a blade's lifetime as well as the aero engine itself. In this chapter, the methods of quantitative metallography (Image Analyzer software NIS - Elements for carbide evaluation, the measurement of secondary dendrite arm-spacing and a coherent testing grid for $\gamma^{\prime}$-phase evaluation) are used for the evaluation of the structural characteristics mentioned above on experimental material - Ni base superalloy ŽS6K.

For instance, a precipitate $\gamma^{\prime}$ size greater than $0.8 \mu \mathrm{m}$ significantly decreases the creep rupture life of superalloys and a carbide size greater than $5 \mu \mathrm{m}$ is not desirable because of the initiation of fatigue cracks (Cetel, A. D. \& Duhl, D. N. 1988).

For this reason, the needs of new methods of the evaluation of non-conventional structure parameters were developed. Quantitative metallography, deep etching and colour-contrast belong to the basic methods. The analysis of quantitative metallography has a statistical nature. The elementary tasks of quantitative metallography are:

- $\quad$ Dendrite arm-spacing evaluation;

- Carbide size and distribution;

- Volume ratio of evaluated gamma prime phase;

- Number ratio of evaluated gamma prime phase;

- Size of evaluated gamma prime phase;

- Protective alitise layer degradation.

The application of quantitative metallography and colour contrast on the ŽS6K Ni-base superalloy are the main objectives discussed in this chapter.

\section{Description of experimental methods and experimental material}

\subsection{Experimental methods}

For the evaluation of structural characteristics the following methods of quantitative metallography were used:

- Carbide distribution and average size was evaluated by the software NIS-Elements;

- Secondary dendrite arm-spacing measurement; 
- $\quad$ For the number of $\gamma^{\prime}$-phase particles, a coherent testing grid with 9 square shape area probes was used;

- For the volume of $\gamma^{\prime}$-phase particles, a coherent testing grid with 50 dot probes made from backslash crossing was used.

Secondary dendrite arm spacing was evaluated according to Figure 6 and calculated with formula (1). The changing of the distance between the secondary dendrite arms " $\mathrm{d}$ " is an important characteristic because of base material, matrix $\gamma$, degradation via the equalising of chemical heterogeneity and also grain size growing.

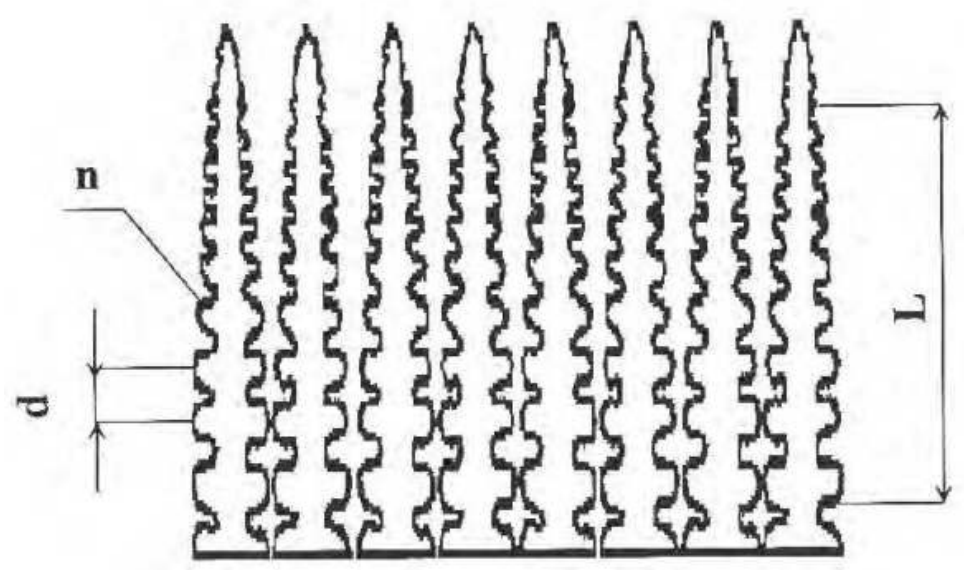

Fig. 6. Scheme for the evaluation of secondary dendrite arm-spacing.

$$
d=\frac{L}{n} \cdot \frac{1}{z} \cdot 1000 \quad(\mu m)
$$

- where " $\mathrm{L}$ " is a selected distance on which secondary arms are calculated (the distance is usually chosen with the same value as used magnification " $z$ " - the reason why this is so is in order to simplify the equation), " $\mathrm{n}$ " is the number of secondary dendrite arms and " $z$ " is the magnification used.

For the evaluation of the $\gamma$ - and $\gamma^{\prime}$-phases the method of coherent testing grid was used, and the number of $\gamma^{\prime}$ "N" was evaluated by a grid with 9 square-shaped area probes (Figure 7a) and the volume of $\gamma^{\prime}$ "V" was evaluated by grid with 50 dot probes (Figure 7b). Afterwards, measurement of the values was calculated with formulas (2) and (3). For a detailed description of the methods used, see (Skočovský \& Vaško 2007, Tillová \& Panušková 2008, Tillová et al. 2011). The size of $\gamma^{\prime}$ is also important from the point of view of creep rupture life. A precipitate with a size higher than $0.8 \mu \mathrm{m}$ can be considered to be heavily degraded and as causing decreasing mechanical strength at higher temperatures. 


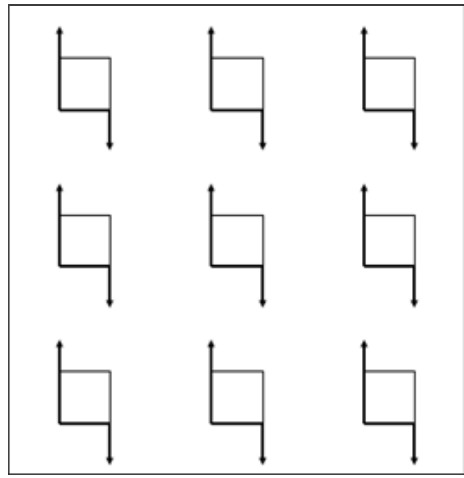

a) number of $\gamma^{\prime}$ particles

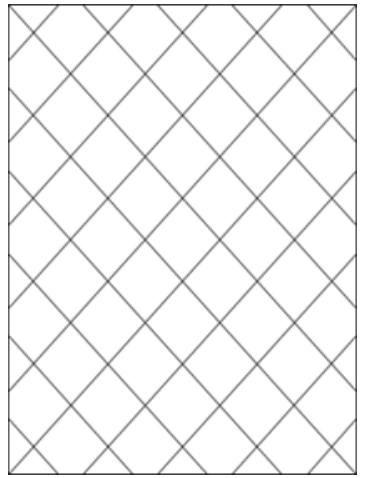

b) volume of $\gamma^{\prime}$ particles

Fig. 7. Coherent testing grid for $\gamma^{\prime}$ evaluation.

$$
N=1,11 \cdot z^{2} \cdot x_{s t r} \cdot 10^{-9} \quad\left(\mu m^{-2}\right)
$$

- where " $\mathrm{N}$ " is a number of $\gamma^{\prime}$ particles, " $\mathrm{z}$ " is the magnification used, " $\mathrm{x}_{\mathrm{str}}$ " is the medium value of $\gamma^{\prime}$-phase measurements.

$$
V=\frac{n_{s}}{n} \cdot 100 \quad(\%)
$$

- where " $\mathrm{V}$ " is a volume of $\gamma^{\prime}$ particles, " $\mathrm{n}_{\mathrm{s}}$ " is the medium value of $\gamma^{\prime}$-phase measurement and " $n$ " is a number of dot probes (when using a testing grid with 50 dot probes, the equation become more simple: $\left.V=2 n_{s}\right)$.

\subsection{Experimental material}

The cast Ni-base superalloy ŽS6K was used as an experimental material. Alloy ŽS6K is a former USSR superalloy which was used in the DV-2 jet engine. It is used for turbine rotor blades and whole-cast small-sized rotors with a working temperature of up to $800 \div 1050^{\circ} \mathrm{C}$. The alloy is made in vacuum furnaces. Parts are made by the method of precise casting. The temperature of the liquid at casting in a vacuum to form is $1500 \div 1600^{\circ} \mathrm{C}$, depending on the part's shape and its quantity. The cast ability of this alloy is very good, with only $2 \div 2.5 \%$ of shrinkage. Blades made of this alloy are also protected against hot corrosion, with a protective heat-proof alitise layer, and so they are able to work at temperatures of up to $750^{\circ} \mathrm{C}$ for 500 flying hours.

This alloy was evaluated at the starting stage, the stage with normal heat treatment after $600,1000,1500$ and 2000 hours of regular working (for these evaluations, real ŽS6K turbine blades with a protective alitise layer were used as an experimental material), and different samples made from the same experimental material ŽS6K after annealing at $800{ }^{\circ} \mathrm{C} / 10$ and $800{ }^{\circ} \mathrm{C} / 15$ hours. This was followed by cooling at various rates in water, oil and air. The chemical composition in wt \% is presented in Table 1.

A typical microstructure of the ŽS6K Ni-base superalloy as cast is shown by Figures 8 and 9 . The microstructure of the as-cast superalloy consists of significant dendritic segregation 


\begin{tabular}{|c|c|c|c|c|c|c|c|c|c|}
\hline C & Ni & Co & Ti & Cr & Al & W & Mo & Fe & Mn \\
\hline $0.13 \div 0.2$ & Bal. & $4.0 \div 5.5$ & $2.5 \div 3.2$ & $9.5 \div 12$ & $5.0 \div 6.0$ & $4.5 \div 5.5$ & $3.5 \div 4.8$ & 2 & 0.4 \\
\hline \multicolumn{7}{|c|}{ Adulterants } & Pb & Bi \\
\hline \multicolumn{2}{|l|}{ P } & S & \multicolumn{3}{c|}{0.001} & 0.0005 \\
\hline
\end{tabular}

Table 1. Experimental alloy's chemical composition.

caused by chemical heterogeneity (Fig. 8a) and particles of primary MC and secondary $\mathrm{M}_{23} \mathrm{C}_{6}$ carbides (Fig. 8b). Primary carbides $\mathrm{MC}$ (where $\mathrm{M}$ is (Ti, Mo and $\mathrm{W}$ )) are presented as block-shaped particles, mainly inside grains. Secondary carbides are presented by "Chinese" script-shaped particles on grain boundaries.

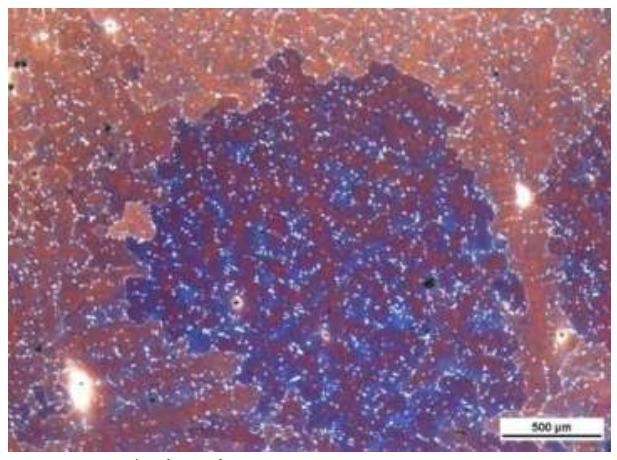

a) dendritic segregation

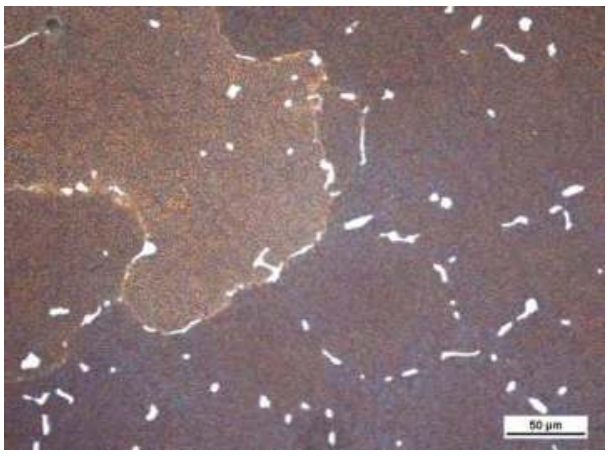

b) $\mathrm{MC}$ and $\mathrm{M}_{23} \mathrm{C}_{6}$ carbides

Fig. 8. Microstructure of as-cast Ni-base superalloy ŽS6K, Beraha III.

However, the microstructure also contains a solid solution of elements in the nickel matrix the so-called $\gamma$-phase $(\mathrm{Ni}(\mathrm{Cr}, \mathrm{Co}$ and $\mathrm{Fe}))$ and strengthening-phase, which is a product of artificial age-hardening and has a significant influence on mechanical properties and creep rupture life - so-called $\gamma^{\prime}$-phase (gamma prime, $\mathrm{Ni}_{3}(\mathrm{Al}$ and $\mathrm{Ti})$ ), Fig. 9a. Of course, both of these phases $-\gamma$ (gamma) and $\gamma^{\prime}$ (gamma prime) - create an eutectic $\gamma / \gamma^{\prime}$, Fig. $9 \mathrm{~b}$.

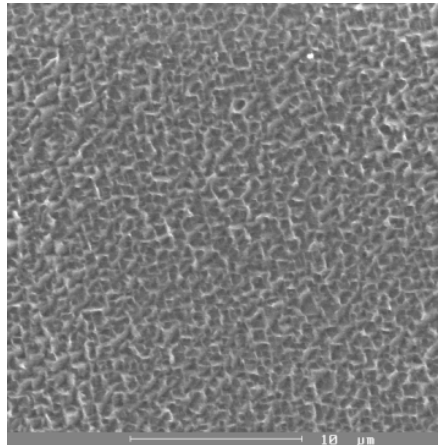

a) matrix and $\gamma^{\prime}$ phases

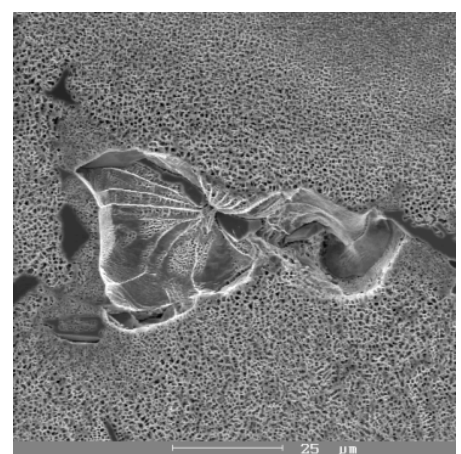

b) $\gamma / \gamma^{\prime}$ eutectic

Fig. 9. Ni-base superalloy ŽS6K microstructure, as-cast. 


\section{Experimental results and discussion}

\subsection{Carbide evaluation}

Polycrystalline and columnar grain alloys contain carbon additions to help improve grainboundary strength and ductility. While the addition of carbon is beneficial to grain boundary ductility, the large carbides that form can adversely affect fatigue life. Both lowand high-cycle fatigue-cracking have been observed to initiate with the large (lengths greater than $0.005 \mathrm{~mm}$ ) carbides presented in these alloys. When polycrystalline alloys were cast in a single crystal form, it was determined that carbides did not impart any beneficial strengthening effects in the absence of grain boundaries, and thus could be eliminated. Producing essentially carbon-free single crystal alloys led to significant improvements in fatigue life as large carbide colonies were no-longer present to initiate fatigue cracks (Cetel, A. D. \& Duhl, D. N. 1988).

The first characteristic were carbide size and its distribution evaluated. Specimens made of the ŽS6K superalloy were compared at the starting stage (non-heat-treated, as-cast) after $800^{\circ} \mathrm{C} / 10 \mathrm{hrs}$ and $800^{\circ} \mathrm{C} / 15 \mathrm{hrs}$. The cooling rate depends on the cooling medium; in our case these were air, oil and water. The results for the ratio of carbide particles in the observed area are in Figure 10 and the results on the average carbide size are in Figure 11.

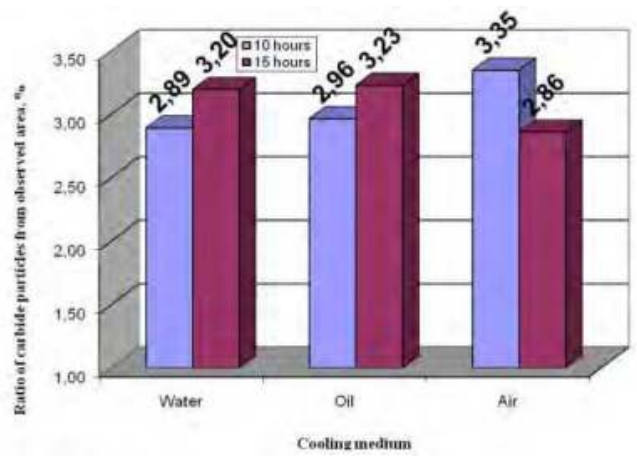

Fig. 10. The ratio of carbide particles from the observed area.

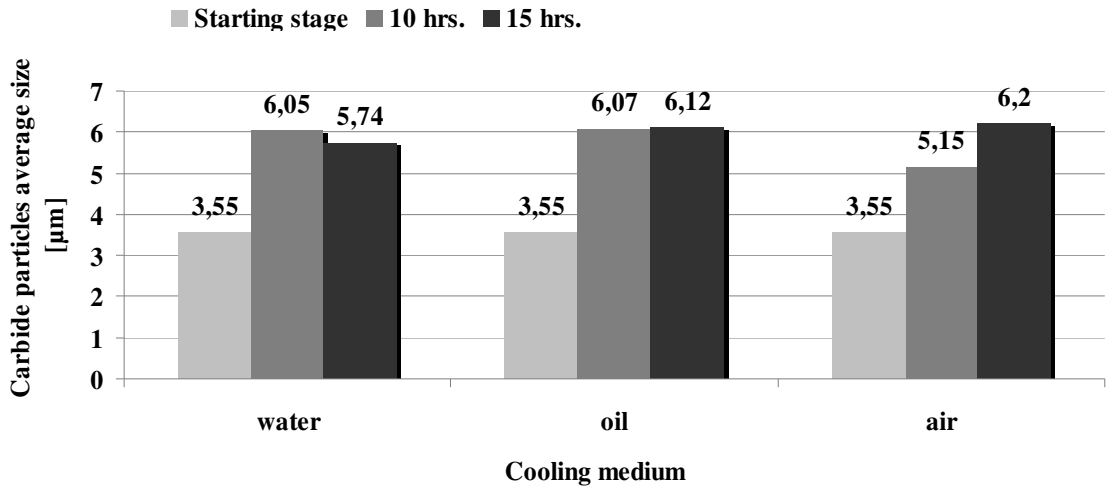

Fig. 11. Average carbide size [ $\mu \mathrm{m}]$. 
From the relations presented (Figure 11) it is obvious that the holding time on various temperatures for annealing and cooling in selected mediums does not have a significant influence on carbide particle size. More significant, the influence on the ratio of carbide particles has a cooling rate (Figure 10). With increasing speed of cooling and a longer holding time on the annealing temperature, the carbide particles' ratio decreases.

Generally, we can suppose that carbide particles are partially dissolved with the temperature of annealing and elements, which are consider as an carbide creators (in this case mainly Ti) have create a new particles of $\gamma^{\prime}$ phase. This phenomenon has an influence on decreasing the segregated carbide percentage ratio. With an increase of the cooling rate (water, oil), an amount of the $\gamma^{\prime}$-phase decreases and the carbides percentage ratio is higher. At slow cooling and a longer time of holding is higher amount of $\gamma^{\prime}$ segregate and, therefore, the ratio of carbides decreases. It is all happen according to scheme:

$$
\mathrm{MC}+\gamma \rightarrow \mathrm{M}_{23} \mathrm{C}_{6}+\gamma^{\prime}
$$

The microstructures which are equivalent to these evaluations are in Figures 12 and 13. For carbide evaluation, etching is not necessary. All of the micrographs are non-etched.
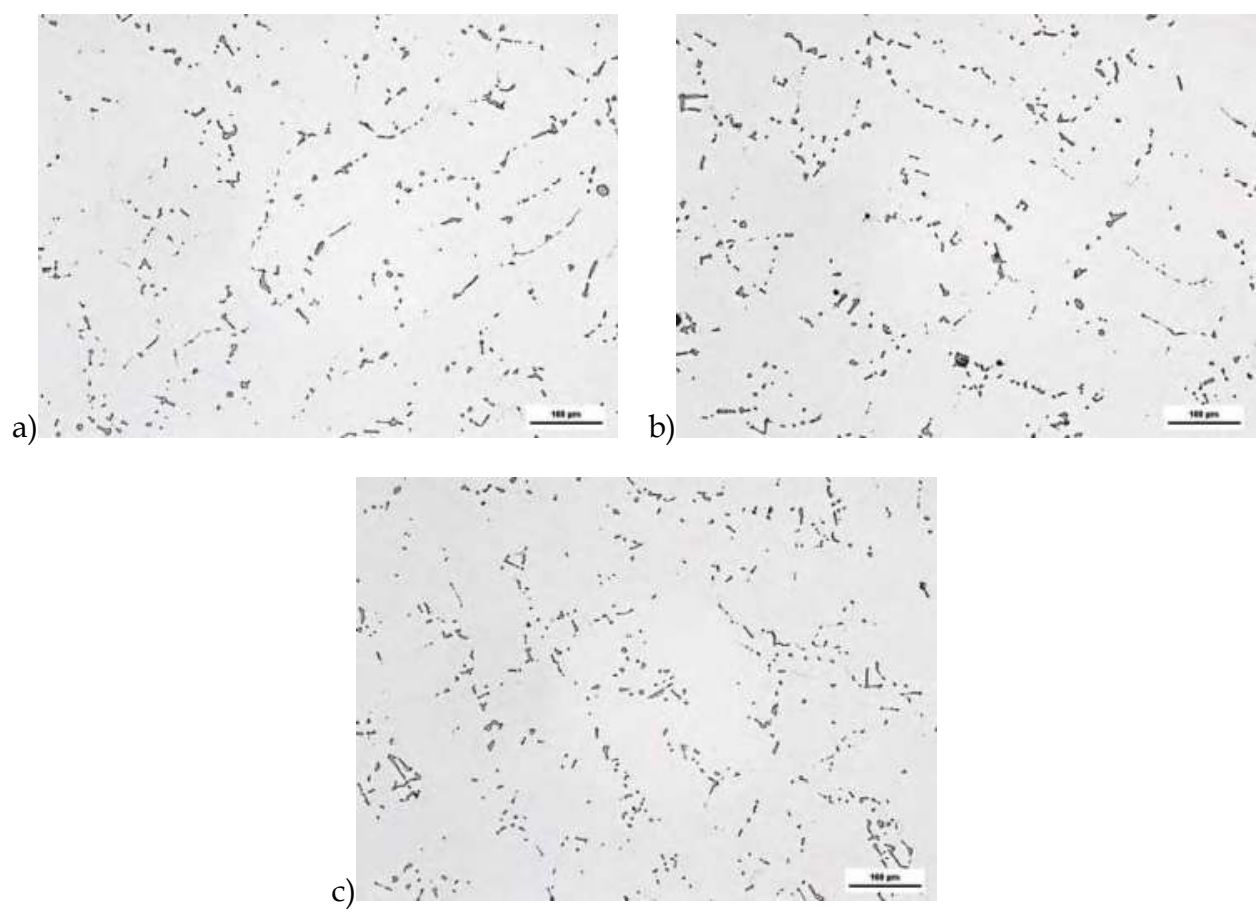

Fig. 12. Microstructure of ŽS6K, carbides ratio after $800^{\circ} \mathrm{C}$ annealing/10 hrs: a) water cooling; b) oil cooling; c) air cooling. 
a)
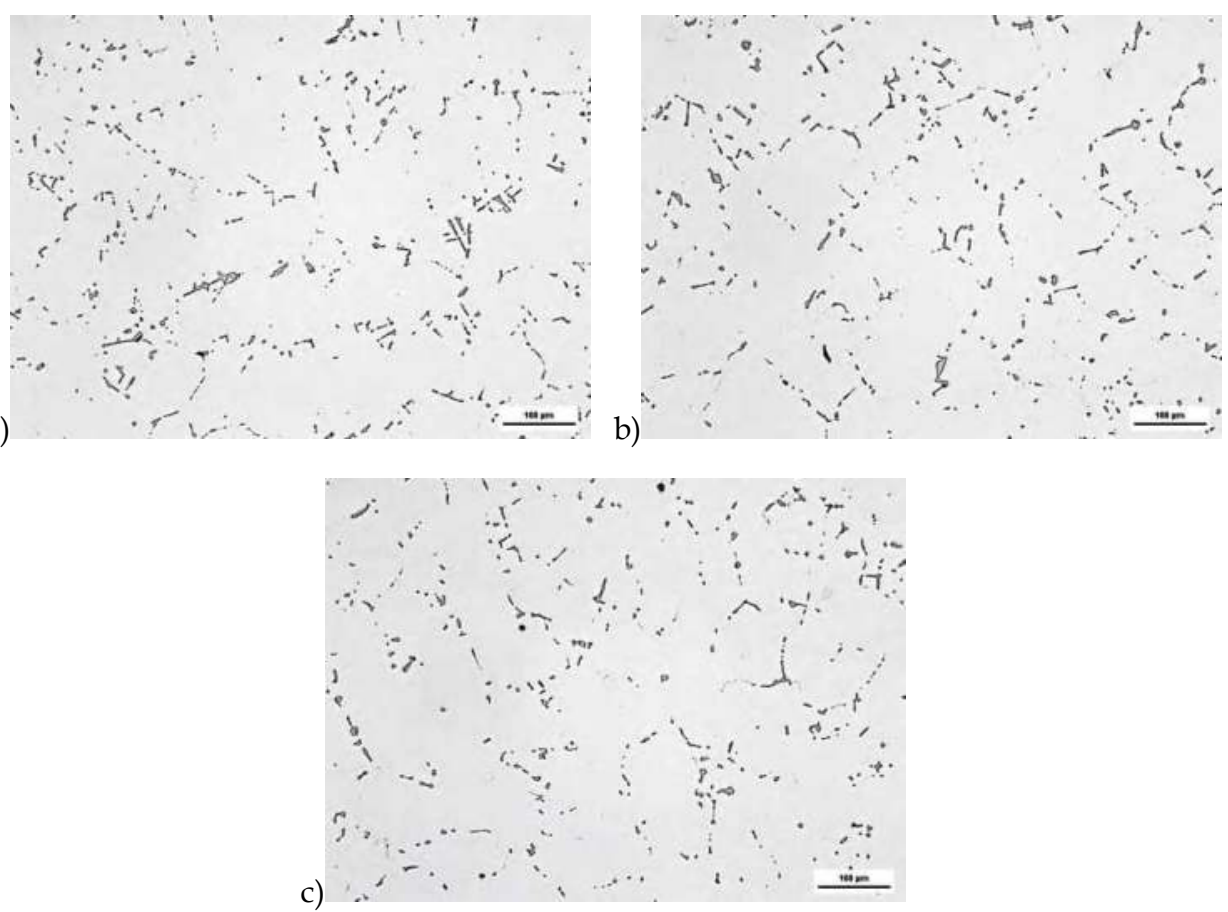

Fig. 13. Microstructure of ŽS6K, carbides ratio after $800^{\circ} \mathrm{C}$ annealing/15 hrs: a) water cooling; b) oil cooling; c) air cooling.

\subsection{Evaluation of secondary dendrite arm-spacing}

The second characteristic which is evaluated is dendrite arm-spacing. In this evaluation, two different approaches were taken. For the first evaluation, non-heat treated ŽS6K specimens were used and compared with loading at $800^{\circ} \mathrm{C} / 10(15) \mathrm{hrs}$. The results of these first evaluations can be seen in Table 2 and Figures 14, 15 and 16. The second evaluation was performed on ŽS6K turbine blades used in the DV-2 (LPT - Low Pressure Turbine and HPT - High Pressure Turbine) aero jet engine at the starting stage (basic heat treatment) and after an engine exposition (at real working temperatures) for 600, 1000, 1500 and 2000 hours. Again, the results are in Table 3 and the microstructures are in Figure 17.

\begin{tabular}{|c|c|c|c|}
\hline \multicolumn{4}{|c|}{ Secondary dendrite arm spacing [ $\mu \mathrm{m}]$} \\
\hline \multicolumn{3}{|c|}{ Cooling medium } \\
\hline ŽS6K - starting stage & Oil & Air \\
\hline & Water & 185.19 \\
\hline ŽS6K/10hrs. & 126.58 & 131.58 & 138.89 \\
\hline ŽS6K/15hrs. & 113.64 & 131.58 & 156.25 \\
\hline
\end{tabular}

Table 2. Results from secondary dendrite arm-spacing for a non-heat treated ŽS6K alloy 


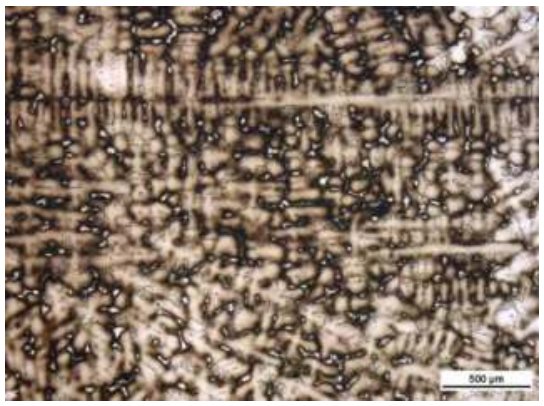

Fig. 14. Dendritic segregation of ŽS6K, starting stage, Marble etchant.

a)

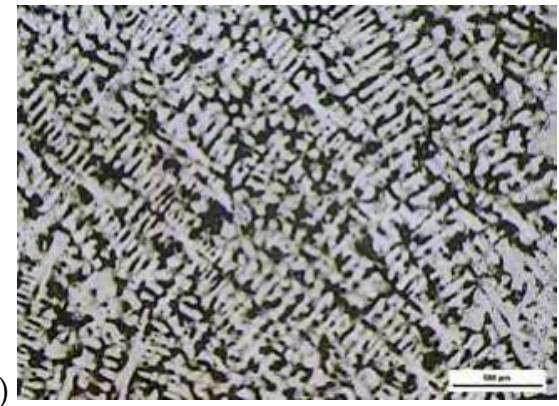

b)
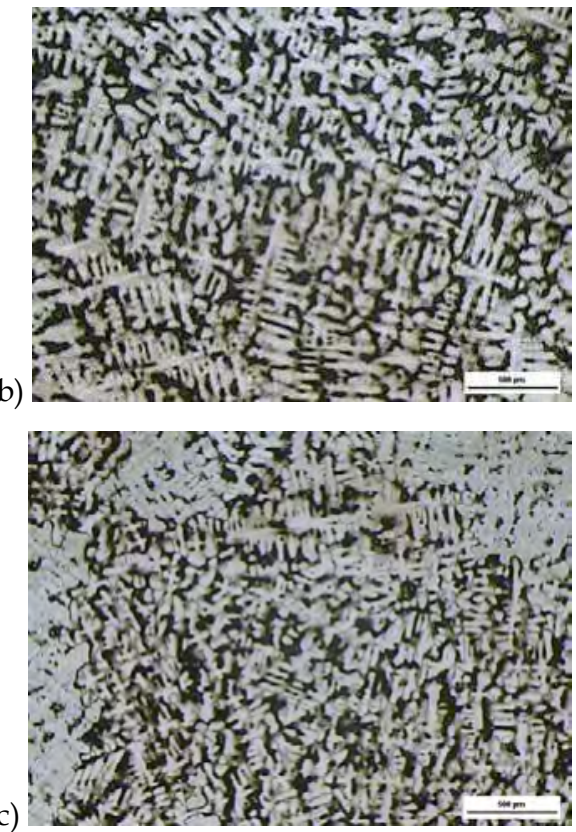

Fig. 15. Dendritic segregation of ŽS6K, $800^{\circ} \mathrm{C} / 10$ hrs: a) water cooling; b) oil cooling; c) air cooling, Marble etchant. 


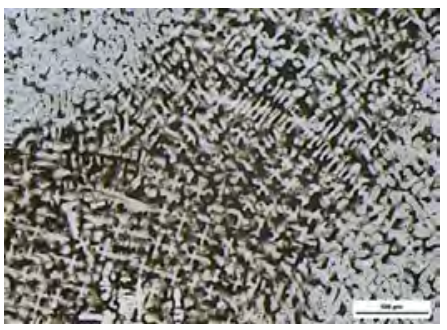

(a)

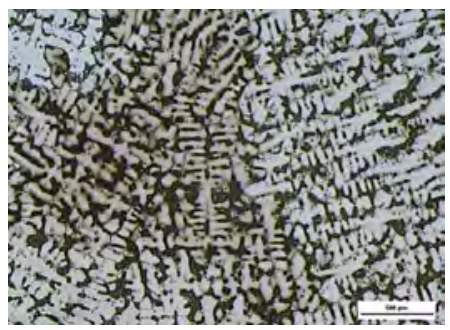

(b)

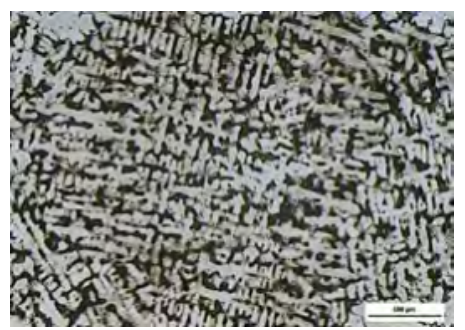

(c)

Fig. 16. Dendritic segregation of ŽS6K, $800^{\circ} \mathrm{C} / 15 \mathrm{hrs} .:$ a) water cooling, b) oil cooling, c) air cooling, Marble etchant.

\begin{tabular}{|l|c|}
\hline \multicolumn{1}{|c|}{ Type of blade } & Secondary dendrite arm-spacing [ $\boldsymbol{\mu m}]$ \\
\hline Blade of 1 ${ }^{\circ} \mathbf{L P T}$ - starting stage & 24.38 \\
\hline Blade of HPT - 600 hrs. & 24.78 \\
\hline Blade of HPT - 1000 hrs. & 27.98 \\
\hline Blade of HPT - 1500 hrs. & 48.73 \\
\hline Blade of HPT - 2000 hrs. & 66.66 \\
\hline
\end{tabular}

Table 3. Results from secondary dendrite arm spacing for real turbine blades, heat-treated ŽS6K alloy.

a)

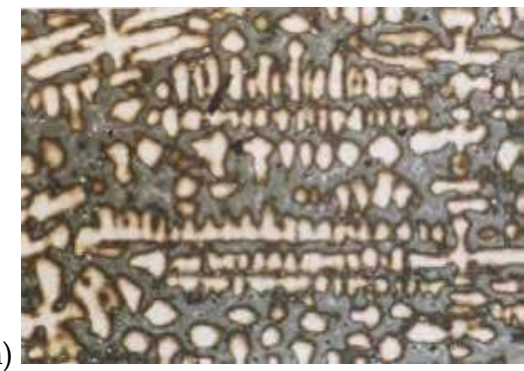

b)

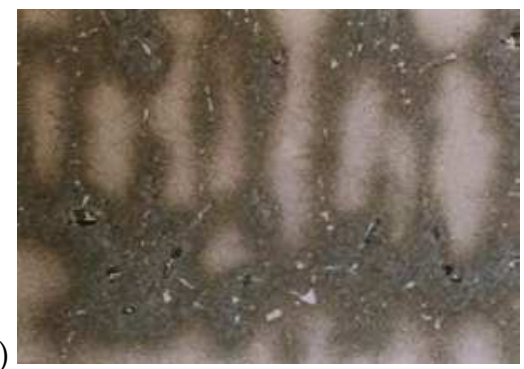

Fig. 17. Dendritic segregation of ŽS6K turbine blades: a) $1^{\circ} \mathrm{LPT}$ - starting stage; b) HPT after 1500 hrs of work, Marble etchant.

The cast materials are characterised by dendritic segregation, which is caused by chemical heterogeneity. With the influence of holding at an annealing temperature, chemical heterogeneity decreases. This means that the distance between secondary dendrite arms 
increases (the dendrites are growing). From the results mentioned above (Table 2), it is clear to see that with a higher cooling rate comes a slowing of the diffusion processes and the dendrite arm-spacing decreases in comparison with the starting stage (Figure 14). All of these changes are also obvious in Figures 15 and 16. The ŽS6K dendrite arm-spacing increases in relation to the annealing time, with an annealing temperature and cooling medium of between 113.64 and $156.25 \mu \mathrm{m}$.

The same phenomena can be observed with heat-treated turbine blades after various working times. Of course, the secondary dendrite arm-spacing is smaller, but again it has a tendency to growth. So, this confirms the results from Table 2: that a longer time of exposure has a significant influence on dendrite and grain size.

\subsection{Evaluation of $\gamma^{\prime}$ morphology}

Since the advanced high-strength nickel-base alloys owe their exceptional high temperature properties to the high volume fraction of the ordered $\gamma^{\prime}$-phase that they contain, it should not be surprising that control of precipitate distribution and morphology can profoundly affect their properties. The post-casting processing of these alloys - especially solution heat treatment - can radically affect microstructure.

The high-strength alloys typically contain about $55 \div 75 \%$ of the $\gamma^{\prime}$ precipitates which, in the cast condition, are coarse $(0.4 \div 1.0 \mu \mathrm{m})$ and irregularly-shaped cuboid particles (see Figure 9).

The evaluation of the $\gamma^{\prime}$-phase is also divided into two parts, just as the dendrite evaluation was. Firstly, the $\gamma^{\prime}$-phase was evaluated on the cast stage, and secondly on turbine blades. The characteristics of $\gamma^{\prime}$-phase morphology were also measured using the coherent testing grid methods. As was mentioned above, the number and volume of the $\gamma^{\prime}$-phase have a significant influence on the mechanical properties of this alloy, especially on creep rupture life. The average satisfactory size of the $\gamma^{\prime}$-phase is about $0.35-0.45 \mu \mathrm{m}$ (Figure 18) and also the carbide size should not exceed a size of $5 \mu \mathrm{m}$ because of fatigue crack initiation (M. J. Donachie \& S. J. Donachie 2002). Another risk in using high temperature loading (or annealing) is the creation of TCP phases - such $\sigma$-phase or Laves-phase - within the temperature range of $750{ }^{\circ} \mathrm{C}-800^{\circ} \mathrm{C}$. The results of first evaluation are in Table 4 . The microstructures related to this evaluation are in Figures 19 and 20.

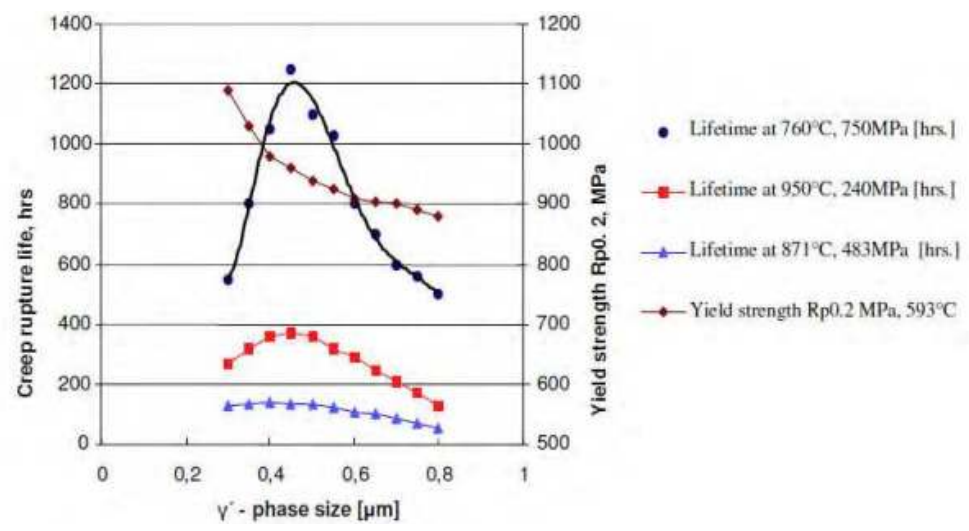

Fig. 18. Influence of $\gamma^{\prime}$-phase size on the lifetime and mechanical properties of Ni superalloy. 


\begin{tabular}{|c|c|c|c|}
\hline $\begin{array}{c}\text { Cooling } \\
\text { medium }\end{array}$ & $\begin{array}{c}\text { Number of } \boldsymbol{\gamma}^{\prime} \text { - phase } \\
\mathbf{N}\left[\mathbf{~ m m}^{-2}\right]\end{array}$ & $\begin{array}{c}\text { Volume of } \boldsymbol{\gamma}^{\prime} \text { - phase } \\
\mathbf{V}[\mathbf{0}]\end{array}$ & $\begin{array}{c}\text { Average size of } \boldsymbol{\gamma}^{\prime} \text { - phase } \\
\mathbf{u}[\boldsymbol{\mu m}]\end{array}$ \\
\hline Start. stage & 2.47 & 39.4 & 0.61 \\
\hline 10h water & 1.95 & 56.2 & 0.54 \\
\hline 10h oil & 1.60 & 63 & 0.63 \\
\hline 10h air & 1.50 & 72.4 & 0.69 \\
\hline 15h water & 1.90 & 66.8 & 0.59 \\
\hline 15h oil & 1.59 & 71.8 & 0.67 \\
\hline 15h air & 1.49 & 76.6 & 0.72 \\
\hline
\end{tabular}

Table 4. Results from $\gamma^{\prime}$-phase evaluation at the cast stage at $800^{\circ} \mathrm{C} / 10(15)$ hrs.

With exposure for 10 hours at an annealing temperature, the volume of $\gamma^{\prime}$-phase was increased by about 16.8-33\% when compared with the starting stage (Figure 19). The significant increase of the $\gamma^{\prime}$-phase was observed at a holding time of 15 hours (Figure 20), and cooling on air, where volume of $\gamma^{\prime}$-phase is $76.6 \%$.

a)

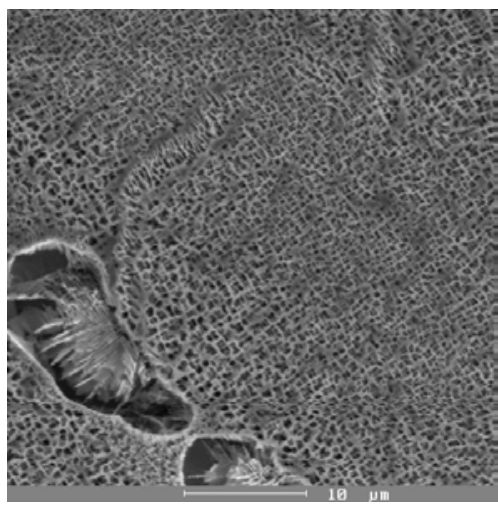

b)

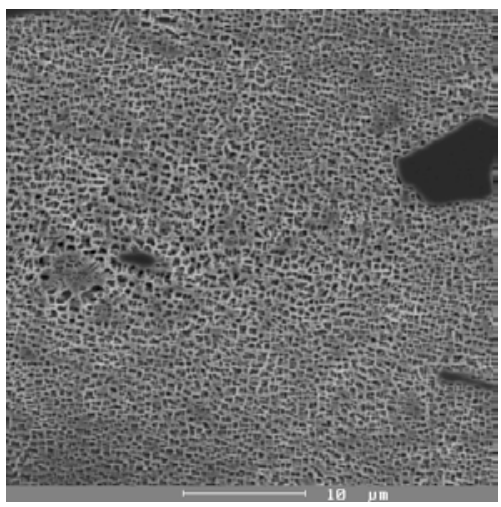

c)

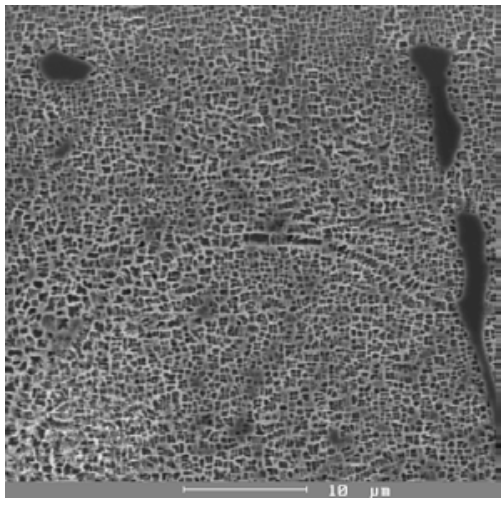

Fig. 19. Morphology of $\gamma^{\prime}$-phase after $800^{\circ} \mathrm{C} / 10 \mathrm{hrs}$ : a) air cooling; b) oil cooling; c) water cooling, Marble etchant, SEM. 
a)

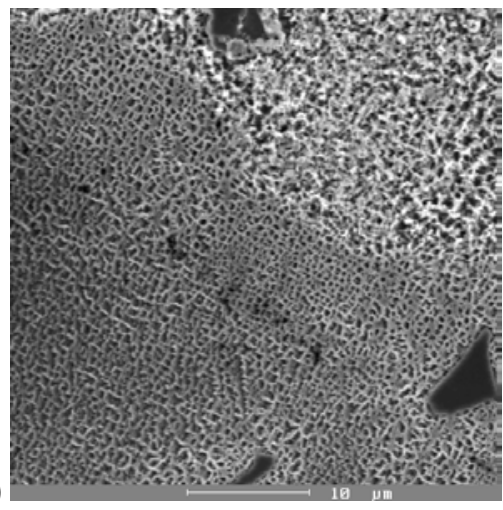

b)

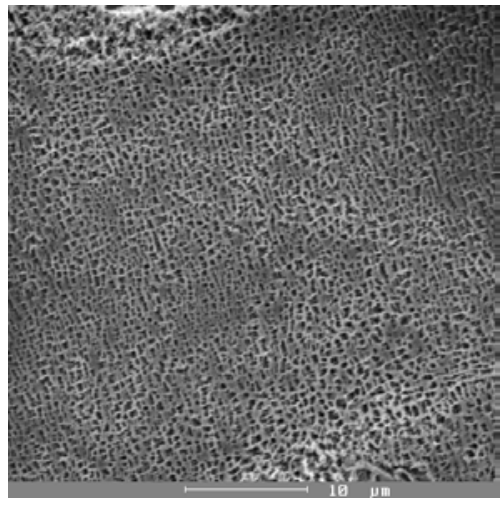

c)

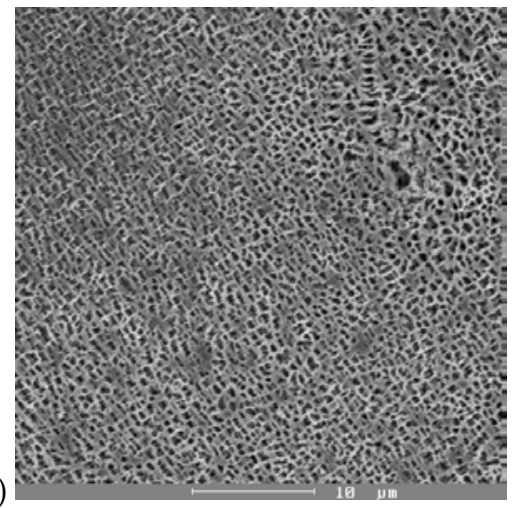

Fig. 20. Morphology of $\gamma^{\prime}$-phase after $800^{\circ} \mathrm{C} / 15 \mathrm{hrs}$ : a) air cooling; b) oil cooling; c) water cooling, Marble etchant, SEM.

The highly alloyed nickel-base alloys solidify dendritically and, due to the effects of chemical segregation across the dendrites, a higher concentration of the $\gamma^{\prime}$-phase forms elements such as aluminium and titanium which are more present in the inter-dendritic areas than in the dendrite core. This results in the $\gamma^{\prime}$ solvus (the temperature at which $\gamma^{\prime}$ first precipitates upon cooling) being lower in the core region than the inter-dendritically region.

Varying the cooling rate from the solution heat treatment temperature can significantly affect the $\gamma^{\prime}$ particle size, as rapid rates do not allow sufficient time for the particles to coarsen as they precipitate upon cooling below the $\gamma^{\prime}$ solvus temperature. Increasing the cooling rate of the solution heat treatment temperature from 30 to $120^{\circ} \mathrm{C} /$ minute results in an average particle size refinement of more than $30 \%$ (Figure 21) (Cetel, A. D. \& Duhl, D. N. 1988).

By controlling both the solution heat treatment and the cooling rate, both the volume fraction of the fine particles as well as their size can be controlled. Heat treating an alloy close to its $\gamma^{\prime}$ solvus temperature and completely dissolving its coarse $\gamma^{\prime}$ particles can produce consistently high-elevated temperature creep-rupture strength. 


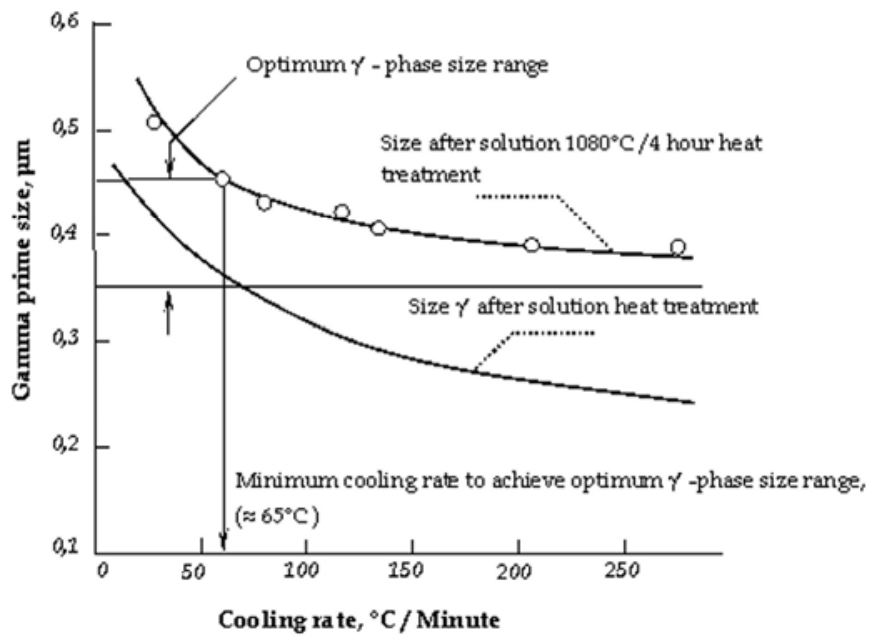

Fig. 21. Optimum $\gamma^{\prime}$ size achieved by rapid cooling of the solution temperature combined with post-solution heat treatment.

Work performed by (Nathal et al. 1987) indicates that the optimum $\gamma^{\prime}$-phase size for an alloy is dependent on the lattice mismatch between the $\gamma$ - and $\gamma^{\prime}$-phases (Figure 22), which is composition dependent.

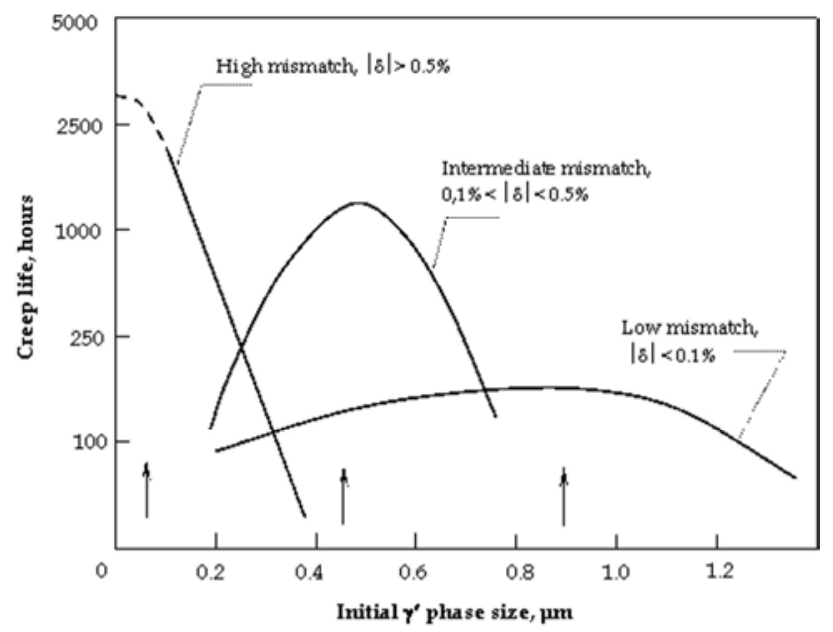

Fig. 22. The optimum $\gamma^{\prime}$-phase size to maximize creep strength is dependent on mismatch between the $\gamma$ - and $\gamma^{\prime}$-phases (Nathal et al. 1987).

The second evaluation of the $\gamma^{\prime}$-phase was provided on heat-treated turbine blades of a DV-2 aero jet engine after various working times. The results obtained are shown by Table 5 . For the evaluation a coherent testing grid was used - the same procedure as in the first evaluation. The microstructures related to this evaluation are shown in Figures 23 and 24. 


\begin{tabular}{|c|c|c|c|}
\hline $\begin{array}{c}\text { Time of work } \\
{[\text { hours] }}\end{array}$ & $\begin{array}{c}\text { Number of } \boldsymbol{\gamma}^{\prime} \text {-phase } \\
\mathbf{N}\left[\boldsymbol{\mu m}^{-2}\right]\end{array}$ & $\begin{array}{c}\text { Volume of } \boldsymbol{\gamma}^{\prime} \text {-phase } \\
\mathbf{V}[\%]\end{array}$ & $\begin{array}{c}\text { Average size of } \boldsymbol{\gamma}^{\prime} \text {-phase } \\
\mathbf{u}\left[\boldsymbol{\mu m}^{2}\right]\end{array}$ \\
\hline $\mathbf{0}$ & 0.98542 & 67.2 & 0.6819 \\
\hline $\mathbf{6 0 0}$ & 1.1242 & 67.6 & 0.60131 \\
\hline $\mathbf{1 0 0 0}$ & 1.1004 & 59 & 0.53615 \\
\hline $\mathbf{1 5 0 0}$ & 0.81938 & 57.4 & 0.7005 \\
\hline $\mathbf{2 0 0 0}$ & 0.6968 & 40.6 & 0.5826 \\
\hline
\end{tabular}

Table 5. Results from the $\gamma^{\prime}$-phase evaluation on heat-treated turbine blades at various working times.

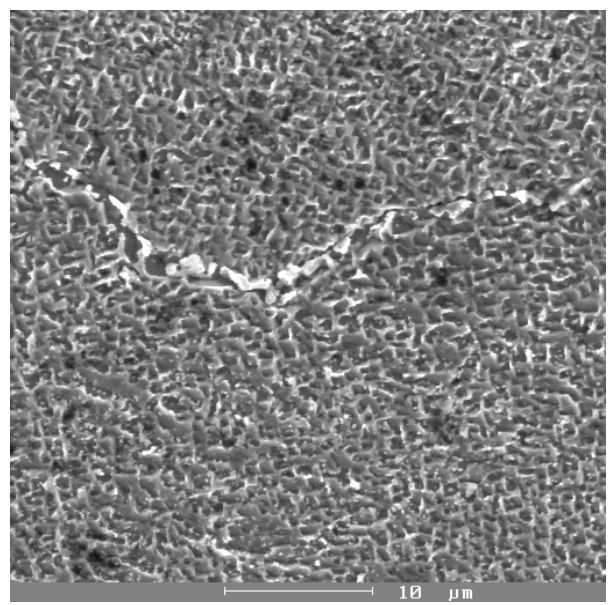

Fig. 23. Morphology of the $\gamma^{\prime}$-phase heat-treated turbine blade, starting stage (0 hours), $\mathrm{HCl}$ $+\mathrm{H}_{2} \mathrm{O}_{2}$ etchant.

The morphology of the $\gamma^{\prime}$-phase at the starting stage is cuboid and distributed equally in the base $\gamma$ matrix (Figure 23.). With an increase of the hours of work at a temperature of up to $750^{\circ} \mathrm{C}$, the $\gamma^{\prime}$-phase morphology changes. The particles of the $\gamma^{\prime}$-phase gradually coarsen (time of work to 1000 hours, Figure $24 \mathrm{a}, \mathrm{b}$ ), which confirms the results of a number of $\gamma^{\prime}$ phase evaluations " $\mathrm{N}$ " (see Table 5). A decrease of this value at a longer duration of work (1500 and 2000 hours) is caused by reprecipitation of new, fine $\gamma^{\prime}$-phase particles in the area between the primal $\gamma^{\prime}$-phase (Figure $24 \mathrm{c}$, d). From the results in Table 5, it is obvious that the $\gamma^{\prime}$-phase of the ŽS6K alloy coarsen uniformly and increase its volume ratio in the structure after up to 1000 hours of exposition (regular work of a jet engine). However, after longer durations of work (1500 or 2000 hours) there occurs the reprecipitation of new, fine particles of the $\gamma^{\prime}$-phase in the free space of matrix and which has caused structural heterogeneity.

In terms of structure degradation and the prediction of the life time of turbine blades - as well as the jet engine itself - and according to the results in Table 5, after up to 1000 hours of exposition the structure (with " $\mathrm{N}$ " $=1.1004, " \mathrm{~V}$ " $=59$ and average size " $\mathrm{u}$ " $=0.53615$ ) is at the "edge" of use because of its mechanical properties, as shown by Figure 18. However, the $\gamma^{\prime}$-phase size is not the only parameter influencing the life time. In addition, the number " $N$ " 
and volume " $\mathrm{V}$ " is important from the point of view of dislocation hardening. When " $\mathrm{N}$ " and " $\mathrm{V}$ " are smaller, this means that the distances between single particles are greater and that fact causes a decrease of the dislocation hardening effect. On the other hand, $\mathrm{M}_{23} \mathrm{C}_{6}$ carbides form a carbide net on the grain boundary which also decreases the creep rupture life by developing brittle grain boundaries. For a comparison of the increasing distance between $\gamma^{\prime}$-phase particles see Figure 25.

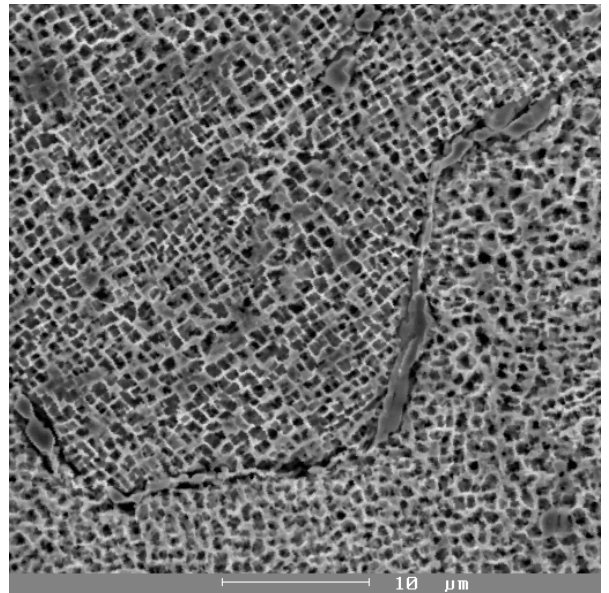

a) 600 hours of exposition

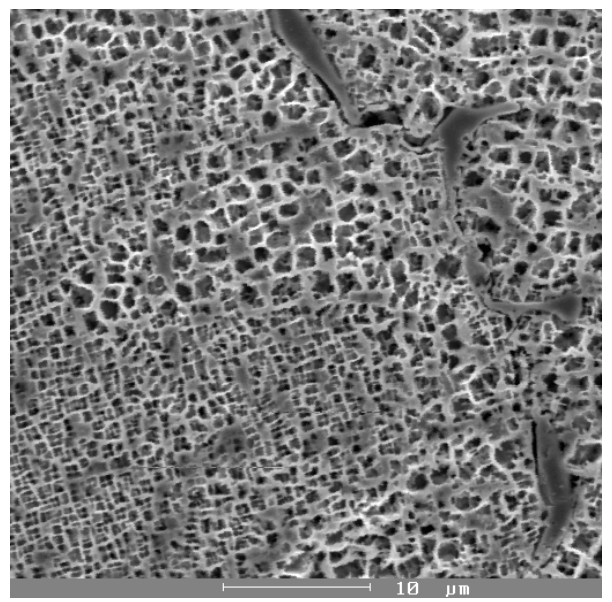

c) 1500 hours of exposition

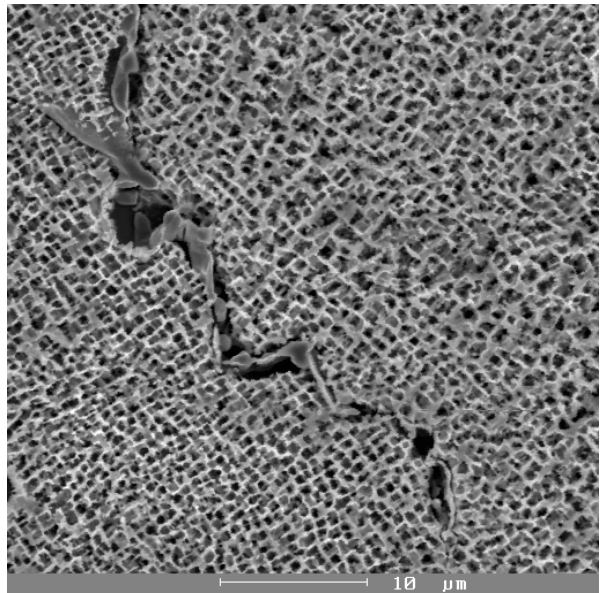

b) 1000 hours of exposition

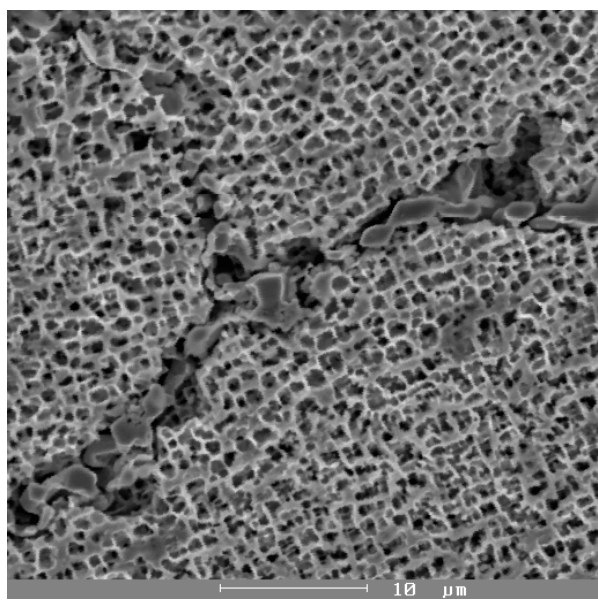

d) 2000 hours of exposition

Fig. 24. Morphology of the $\gamma^{\prime}$-phase, heat treated turbine blade made of the ŽS6K alloy, after various exposition, $\mathrm{HCl}+\mathrm{H}_{2} \mathrm{O}_{2}$ etchant. 


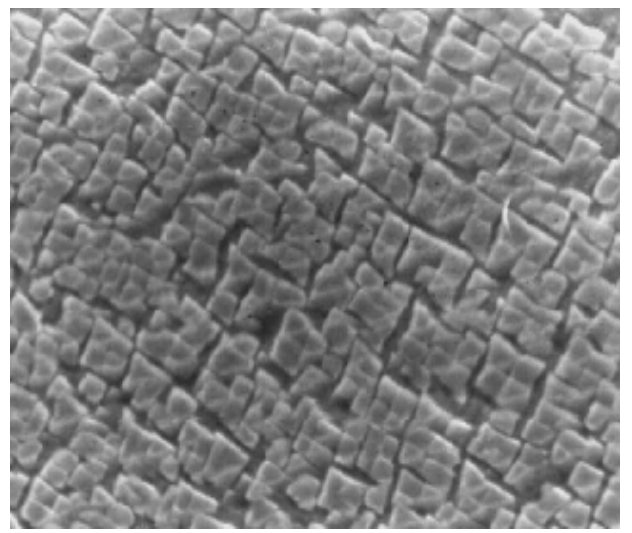

a) starting stage

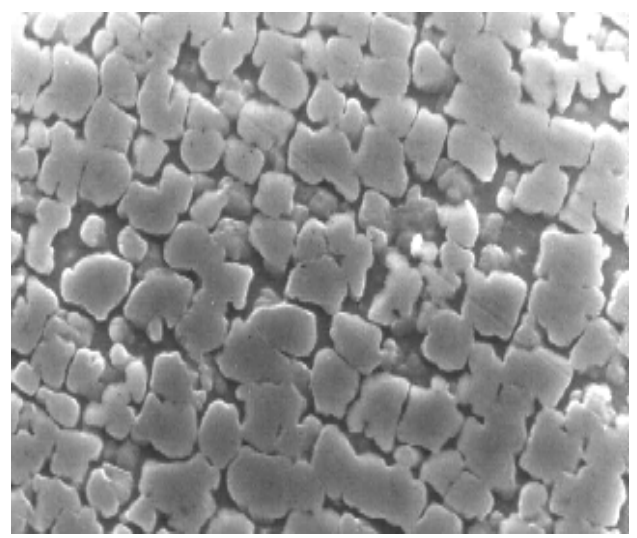

c) 1500 hours of exposition

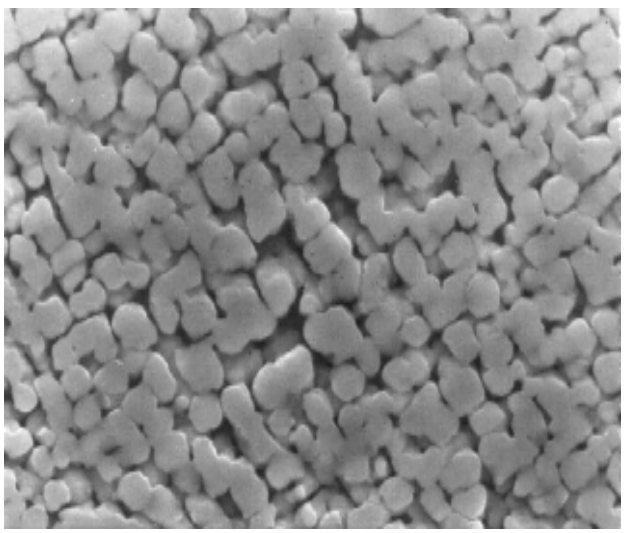

b) 600 hours of exposition

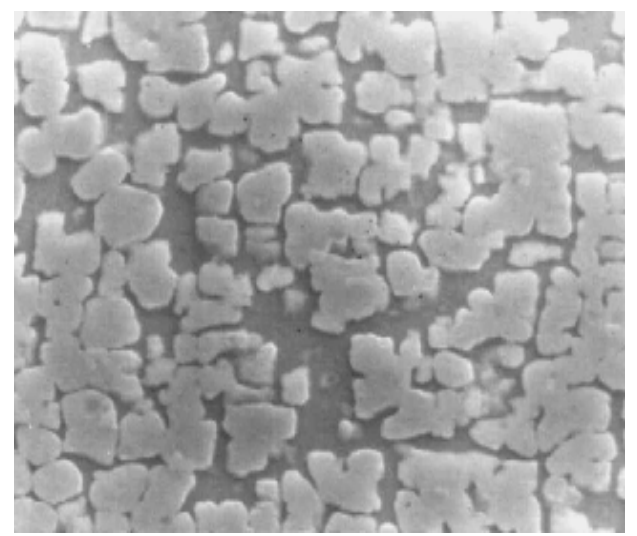

d) 2000 hours of exposition

Fig. 25. Detail of the ŽS6K alloy's $\gamma^{\prime}$-phase showing the increasing distance between $\gamma^{\prime}$ particles as an affect of working exposition - at normal working loading of a jet engine which has a significant influence on the dislocation hardening effect.

\subsection{Evaluation of the Al-Si protective layer}

To improve the lifetime of turbine blades made from the ŽS6K alloy against a hot corrosion environment, an alitise Al-Si protective layer is used. What is important about this kind of layer is that it does not improve the high temperature properties of the base alloy but only its hot corrosion resistance.

An alitise layer is used for the protection of HPT blades (Figure 26) and only $1^{\circ}$ of LPT blades, which means that Al-Si suspension is applied on to the surface of the blades. Silicon is added due to its ability to increase resistance to corrosion in sulphide and sea environments. Generally, an alitise layer AS-2 type is used for corrosion protection of aero gas turbine parts which work at temperatures of up to $950{ }^{\circ} \mathrm{C}$; type AS- 1 up to a temperature of $1100{ }^{\circ} \mathrm{C}$ (DV-2-I-62: Company standard). The standard procedure of applying Al-Si protective coating is in Table 6 . 


\begin{tabular}{|c|c|}
\hline Heat - treatment & Conditions \\
\hline $\begin{array}{l}\text { Homogenization } \\
\text { annealing }\end{array}$ & $\begin{array}{l}\text { In vacuum, temperature } 1225^{\circ} \mathrm{C} \text {, holding } 4 \mathrm{hrs} \text {, cooling with } \\
\text { argon to } 900^{\circ} \mathrm{C} \text { per } 10 \mathrm{~min} .\end{array}$ \\
\hline \multirow[t]{2}{*}{ Alitise AS2 } & $\begin{array}{c}\text { 1. Spraying of AS2 layer } \\
\text { (AS2 - koloxylin solution } 350 \mathrm{ml}, \mathrm{Al} \text { - powder } 112 \mathrm{~g}, \mathrm{Si} \text { - powder } \\
112 \mathrm{~g})\end{array}$ \\
\hline & $\begin{array}{c}\text { 2. Diffusion annealing } \\
\text { temperature } 1000^{\circ} \mathrm{C}, 3 \mathrm{hrs} \text {, slowly cooled in retort }\end{array}$ \\
\hline
\end{tabular}

Table 6. Steps for protective Al-Si coating as applied on to a ŽS6K turbine blade.
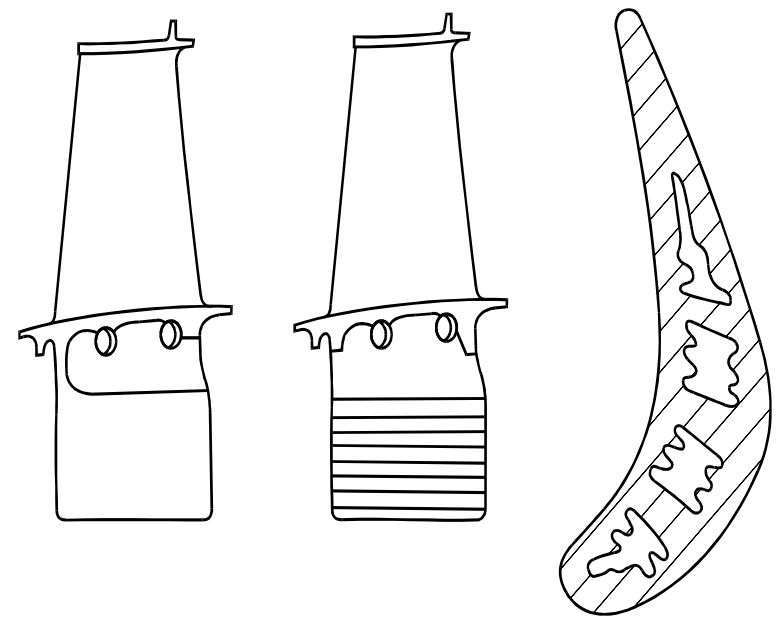

Fig. 26. A high pressure turbine blade of a DV-2 aero jet engine, left-side, right-side and cross-section with cooling chambers.

The Al-Si layer consists of two layers at the starting stage. The upper layer (the aluminiumrich layer) is created by aluminides - a complex compound of $\mathrm{Si}, \mathrm{Cr}$ and $\mathrm{Mo}$ - and by carbides. The lower part of layer (the silicon rich layer) is created mainly by silicon and titanium carbides and the $\gamma$ matrix. The average thickness of the layer is $0.04 \mathrm{~mm}$. According to the evaluation by metallography, the alitise layer is equally distributed across the whole blade surface at the starting stage (Figure $27 \mathrm{a}, \mathrm{b}$ ).

In cases of overheating (here, at $1000^{\circ} \mathrm{C}$ - the normal working temperature is $705^{\circ} \mathrm{C} \div 750^{\circ} \mathrm{C}$ ) the alitise layer is significantly degraded (Figure $27 \mathrm{c}$, d). The layer is non-homogeneous, with a rough surface and in place of the flow edge in the area of the flap pantile is a layer which is evenly broken (Figure 27d). Layer degradation is connected with the diffusion of elementary elements - such as $\mathrm{Cr}, \mathrm{Ti}, \mathrm{Ni}$ and $\mathrm{Al}$ - from the base material into the surface area (Table 7.). Where $\mathrm{Cr}$ and $\mathrm{Ti}$ creates carbides, $\mathrm{Ni}$ and $\mathrm{Al}$ form fine $\gamma^{\prime}$ particles and $\mathrm{Al}$ as itself also creates $\mathrm{NiAl}$ ( $\beta$-phase) and $\mathrm{Al}_{2} \mathrm{O}_{3}$ oxides on the surface of the layer. With decreasing of the layer's heat resistance, the base material is impoverished, which leads to the growth of $\gamma^{\prime}$ particles and decreasing of its volume. 
a)

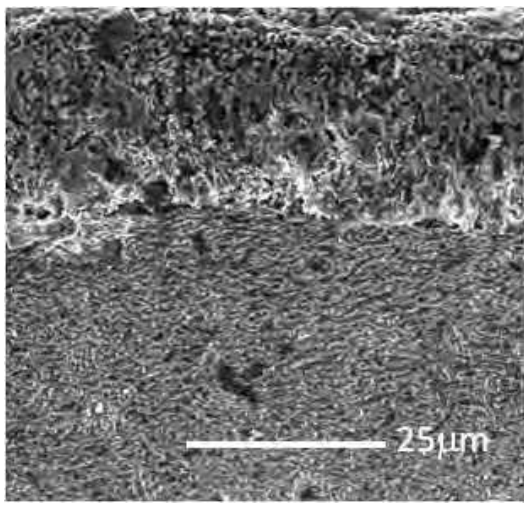

c)

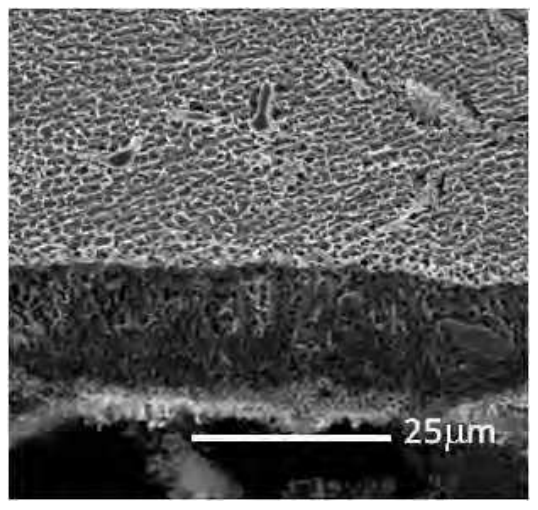

b)

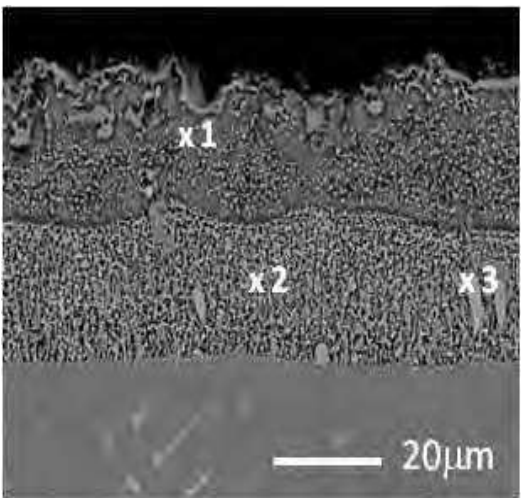

d)

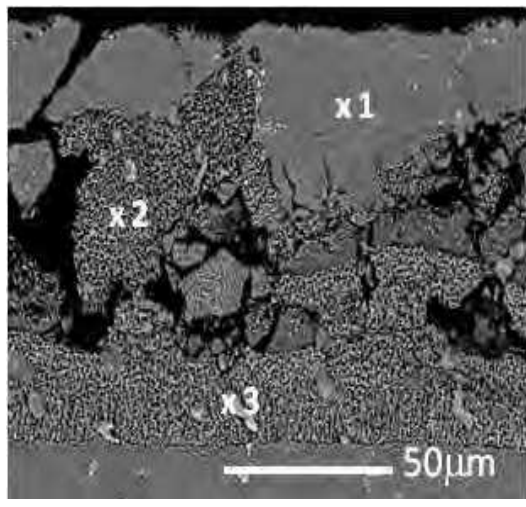

Fig. 27. Alitise layer a, b) starting stage; c, d) after overheating at $1000^{\circ} \mathrm{C}, \mathrm{SEM}$.

\begin{tabular}{|c|c|c|c|c|c|c|c|c|c|}
\hline Sample & Marked spots & $\mathrm{AlK}$ & $\mathrm{SiK}$ & $\mathrm{MoK}$ & $\mathrm{TiK}$ & $\mathrm{CrK}$ & $\mathrm{CoK}$ & $\mathrm{NiK}$ & $\mathrm{Wk}$ \\
\hline \multirow{3}{*}{\begin{tabular}{c} 
Starting stage, Fig. 27b \\
\cline { 2 - 10 }
\end{tabular}} & 1 & 19.7 & 2.21 & 0.23 & 0.83 & 6.54 & 4.14 & 65.5 & 0.34 \\
\cline { 2 - 10 } & 2 & 15.01 & 3.09 & 2.56 & 2.28 & 5.16 & 4.06 & 65 & 2.27 \\
\hline $\begin{array}{c}\text { Overheating at } 1000^{\circ} \mathrm{C}, \\
\text { Fig. 27d }\end{array}$ & 1 & 1.57 & 7.57 & 17.51 & 5.82 & 13.53 & 3.01 & 28.45 & 21.94 \\
\cline { 2 - 9 } & 2 & 18.04 & 5.94 & 7.42 & 0.92 & 9.25 & 4.15 & 52.6 & 10.6 \\
\cline { 2 - 9 } & 3 & - & 9.54 & 13.5 & 9.5 & 11.3 & 3.25 & 33.1 & 19.6 \\
\hline
\end{tabular}

Table 7. Spot analysis of selected particles. The marked spots (in $\mathrm{wt} \%$ ) correspond with Figure 27b, $d$.

The alitise layer on the blades which have worked at regular conditions is also degraded, which is represented by the changing of the layer thickness and the surface relief. Changes in layer thickness are caused by heterogeneity of the temperature field along the blade and the abrasive and erosive effect of gases and exhaust gases. The level of layer degradation varies, depending on the area of blade. From a metallographic point of view, the highest degradation is in the flap pantile region close to the flow edge, in the case of blades after 
1500 and 2000 hours of work (Figure 28 c, d). In region close to the Si sub-layer, needle particles (probably a special form of $\mathrm{Cr}$ base carbides) are created which grow depending upon the time of work (compare Figures $27 \mathrm{a}, \mathrm{b}$ and 28). These needle particles start to form after 600 hours of loading, which means that after 600 (Figure 28 a, b) hours of work and aero jet engine should to be taken in for overhauling and the old alitise layer replaced by a new one. However, when it comes to the local overheating of the turbine blades, all of the degradation processes are much faster.

a)
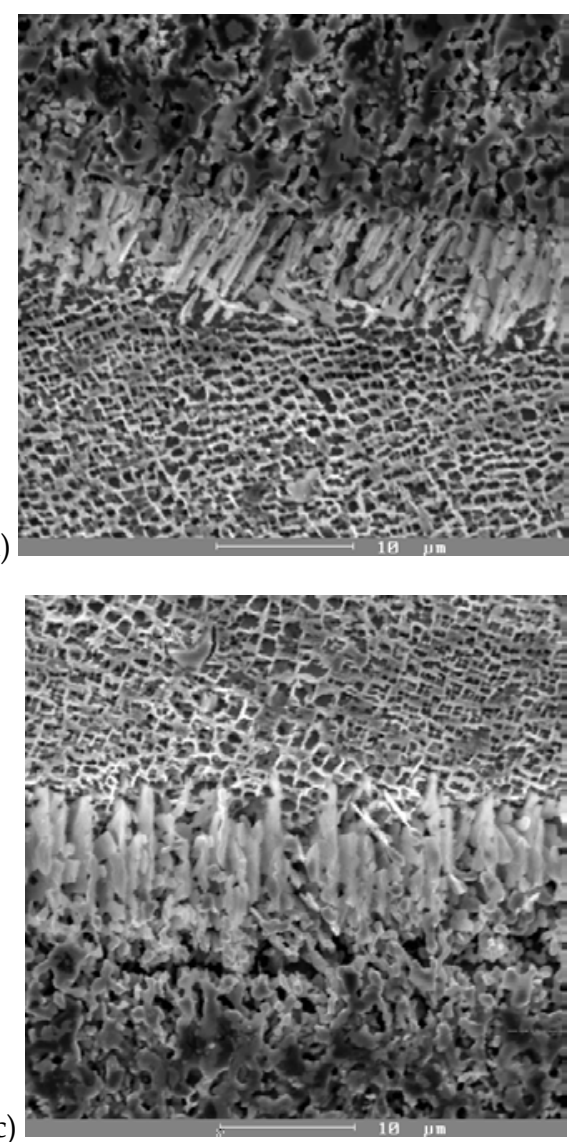

b)

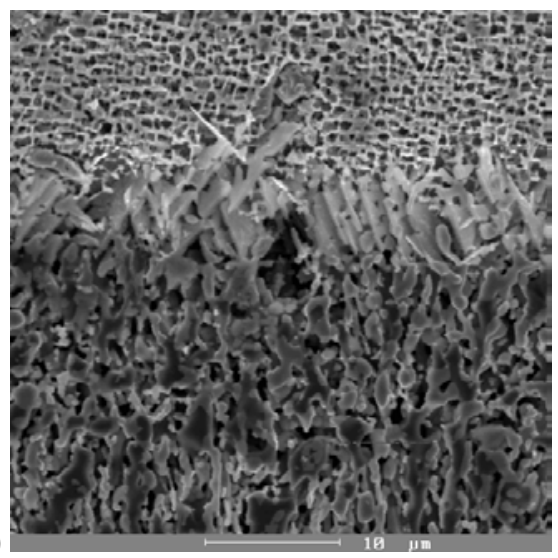

d)

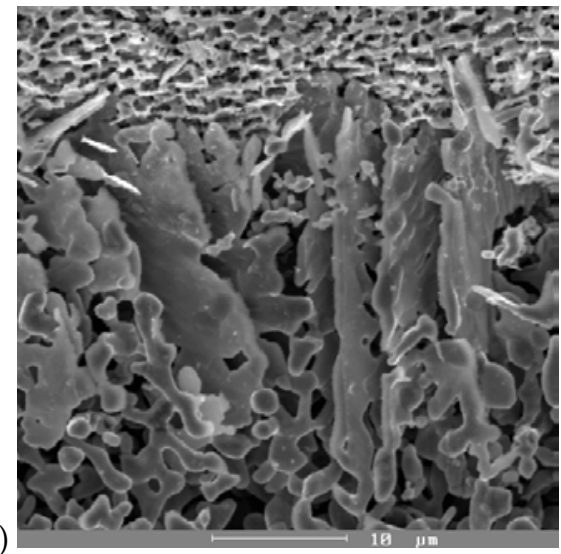

Fig. 28. Creation of needle particles in the region under the Si sub-layer: a) 600 hours; b) 1000 hours; c) 1500 hours; d) 2000 hours of regular work, SEM, Marble etchant.

\section{Conclusion}

As cast Ni-base ŽS6K superalloy was used as an experimental material, the structural characteristics were evaluated from the starting stage of the sample, after annealing at $800^{\circ} \mathrm{C} / 10$ and $800^{\circ} \mathrm{C} / 15 \mathrm{hrs}$ and after various working times in real jet engines with the use of the methods of quantitative metallography. The results are as follows: 
- The structure of the samples is characterised by dendritic segregation. In dendritic areas, fine $\gamma^{\prime}$-phase is segregated. In inter dendritic areas, eutectic cells $\gamma / \gamma^{\prime}$ and carbides are segregated.

- The holding time (10-15 hrs.) has a significant influence on the carbide particles' size. The size of the carbides is under a critical level for the initiation of fatigue crack only at the starting stage. An increase in the rate of cooling has a significant effect on the carbide particles' ratio.

- The chemical heterogeneity of the samples with a longer holding time decreases. This is a reason of the fact that there is sufficient time for the diffusion mechanism, which is confirmed by the measurement results of secondary dendrite arm-spacing.

- $\quad$ The volume of the $\gamma^{\prime}$-phase with a longer holding time increases and the $\gamma^{\prime}$-phase size grows. With a higher rate of cooling the $\gamma^{\prime}$ particles become finer.

- There was no evidence of the presence of TCP phase even at a high annealing temperature.

- Cooling rate also has an influence on the hardness. At a lower rate of cooling, the internal stresses are relaxed, which causes hardness to increase - a changing of the dislocation structure.

The cooling rates, represented by various cooling mediums, have a significant influence on the diffusion processes which are operating within the structure. These diffusion processes are the main mechanisms for the formation and segregation of carbide particles, the equalising of chemical heterogeneity (represented by dendrite arm-spacing) and segregation of the $\gamma^{\prime}$-phase; they are also responsible for structural degradation of such alloys.

Air - as a cooling medium - provides sufficient time for the realisation of diffusion reactions and it leads to a decrease of chemical heterogeneity, which is presented by an increase of secondary dendrite arm-spacing. Also, this "slow" cooling rate has a positive effect on carbides' segregation and on the morphology, number and volume of the strength precipitate $\gamma^{\prime}$ (the precipitate has a greater diameter and its volume increases).

Water is the most intensive cooling medium, which breaks diffusion processes and which leads to an increase of carbide particles in the observed area; the precipitate $\gamma^{\prime}$ is smaller, increasing the hardness and at least also increasing the strength.

From a general point of view we can perform cooling in oil, which might be consider as a medium point between cooling in air and cooling in water.

For the turbine blades, which have been worked at normal loading and for various durations (600, 1000, 1500 and 2000 hours), the following results were achieved:

- The medium distance of secondary dendrite arms " $\mathrm{d}$ " grows in dependence on the time of work, caused by changes of the grain size of the $\gamma$-matrix.

- The gradual dissolving of primary carbides rests and the reprecipitation of secondary carbides on grain boundary. After longer durations of work (1000-2000 hours) it changes its chain morphology onto the carbide net, which has a significant influence on lowering the mechanical properties of the alloy.

- The inter-metallic phase- $\gamma^{\prime}$ was evaluated with the methods of quantitative metallography; this evaluation shows gradual morphology changes of the $\gamma^{\prime}$-phase coarsening, spheroidisation and reprecipitation. 
- The alitise layer degradation was expressed by a changing thickness and needle-like $\mathrm{Cr}$ carbide segregation at the sub-layer region, which has a negative influence on the layer's lifetime. There is strong recommendation for overhauling after every 500 hours of regular work.

\section{Acknowledgment}

The authors acknowledge the financial support of the projects VEGA No. 1/0841/11 and No. 1/0460/11; KEGA No. 220-009ŽU-4/2010 and European Union - the Project "Systematization of advanced technologies and knowledge transfer between industry and universities (ITMS 26110230004)".

\section{References}

ASM. (1992). ASM Handbook Volume 3: Alloy Phase Diagrams (10th edition), ASM International, ISBN 0-871-70381-5, USA.

Cetel, A. D. \& Duhl, D. N. (1988). Microstructure - Property Relationships In Advanced Nickel Base Superalloy Airfoil Castings, 2nd International SAMPE Metals Conference, pp. 37-48, USA, August 2-4, 1988.

Donachie, M. J. \& Donachie, S. J. (2002). Superalloys - A technical Guide (2nd edition), ASM International, ISBN 0-87170-749-7, USA.

Durand-Chare, M. (1997). The Microstructure of Superalloys, Gordon \& Breach Science Publishers, ISBN 90-5699-097-7, Amsterdam, Netherlands.

DV-2-I-62: Company standard, Považské machine industry, Division of Aircraft Engine DV-2, Považská Bystrica, Slovakia, 1989.

MacSleyne, J. P. (2008). Moment invariants for two-dimensional and three-dimensional characterization of the morphology of gamma-prime precipitates in nickel-base superalloys, In: Doctoral Thesis / Dissertation, n.d., Available from:

<http://www.grin.com/en/doc/263761/moment-invariants-for-two-dimensionaland-three-dimensional-characterization>

Nathal, M. V. (1987) Met. Trans., Vol. 18 A, pp. 1961-1970.

Reed, R. C. (2006). The superalloys: fundamentals and applications, Cambridge University Press, ISBN 0-521-85904-2, New York, USA.

Sims, Ch. T., Stoloff, N. S. \& Hagel, W. C. (1987). Superalloys II (2nd edition), WileyInterscience, ISBN 0-471-01147-9, USA.

Skočovský, P. \& Vaško, A. (2007). The quantitative evaluation of cast iron structure (1 ${ }^{\text {st }}$ edition), EDIS, ISBN 978-80-8070-748-4, Žilina, Slovak Republic.

Tillová, E. \& Panuškova, M. (2008). Effect of Solution Treatment on Intermetallic Phase's Morphology in AlSi9Cu3 Cast Alloy. Mettalurgija/METABK, No. 47, pp. 133-137, 14, ISSN 0543-5846.

Tillová, E., Chalupová, M., Hurtalová, L., Bonek, M., \& Dobrzanski, L. A. (2011). Structural analysis of heat treated automotive cast alloy. Journal of Achievements in Materials and Manufacturing Engineering/JAMME, Vol. 47, No. 1, (July 2011), pp. 19-25, ISSN 1734-8412. 


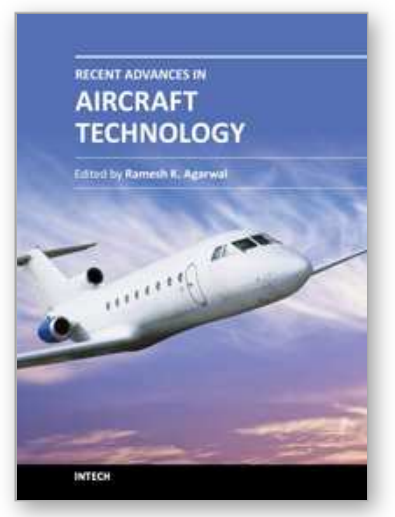

\author{
Recent Advances in Aircraft Technology \\ Edited by Dr. Ramesh Agarwal
}

ISBN 978-953-51-0150-5

Hard cover, 544 pages

Publisher InTech

Published online 24, February, 2012

Published in print edition February, 2012

The book describes the state of the art and latest advancements in technologies for various areas of aircraft systems. In particular it covers wide variety of topics in aircraft structures and advanced materials, control systems, electrical systems, inspection and maintenance, avionics and radar and some miscellaneous topics such as green aviation. The authors are leading experts in their fields. Both the researchers and the students should find the material useful in their work.

\title{
How to reference
}

In order to correctly reference this scholarly work, feel free to copy and paste the following:

Juraj Belan (2012). Study of Advanced Materials for Aircraft Jet Engines Using Quantitative Metallography, Recent Advances in Aircraft Technology, Dr. Ramesh Agarwal (Ed.), ISBN: 978-953-51-0150-5, InTech, Available from: http://www.intechopen.com/books/recent-advances-in-aircraft-technology/study-of-advancedmaterials-for-aircraft-jet-engines-using-quantitative-metallography-

\section{INTECH}

open science | open minds

\section{InTech Europe}

University Campus STeP Ri

Slavka Krautzeka 83/A

51000 Rijeka, Croatia

Phone: +385 (51) 770447

Fax: +385 (51) 686166

www.intechopen.com

\section{InTech China}

Unit 405, Office Block, Hotel Equatorial Shanghai

No.65, Yan An Road (West), Shanghai, 200040, China 中国上海市延安西路65号上海国际贵都大饭店办公楼 405 单元

Phone: +86-21-62489820

Fax: $+86-21-62489821$ 
(C) 2012 The Author(s). Licensee IntechOpen. This is an open access article distributed under the terms of the Creative Commons Attribution 3.0 License, which permits unrestricted use, distribution, and reproduction in any medium, provided the original work is properly cited. 